\title{
الهجرة الدولية في خضم عالم غارق في الأزمات***
}

\section{International Migration amid a World in Crisis}

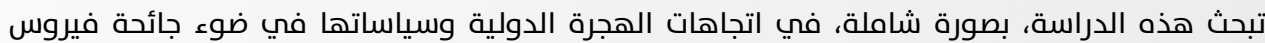
كورونا المستجد (كوفيد-19)، وتبدأ باستعراض المراحل التي مرّت بها الهجرة الهرة خلآ الدهال الأعوام الستّين الماضية.

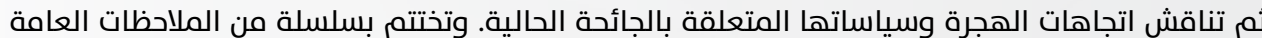

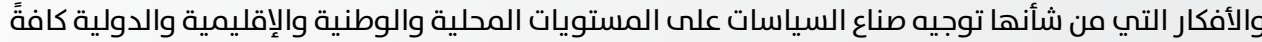

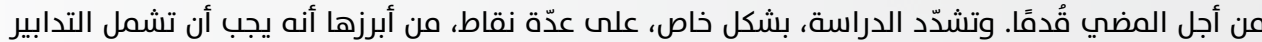

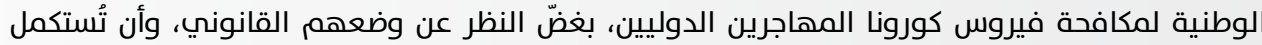

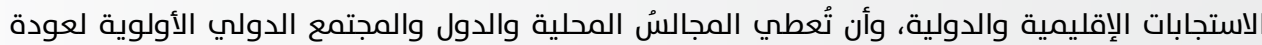

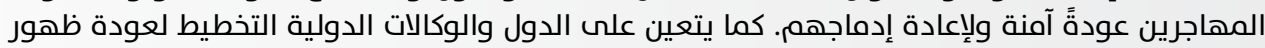

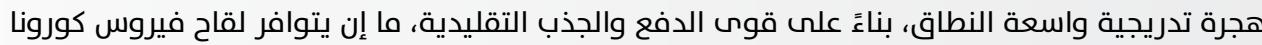

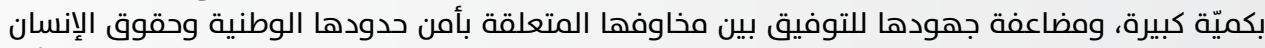

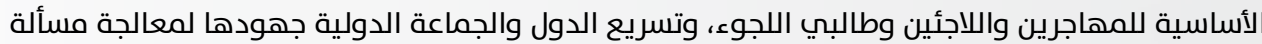

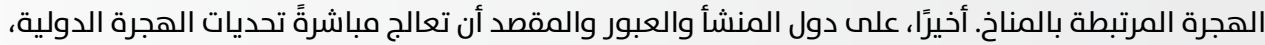
لا أن تكتفيَي بالتخفيف من أهميتها.

كلمات مفتاحية: الهجرة، الحركة، المهاجرون، اللاجئون.

This article comprehensively examines international migration trends and policies in light of the coronavirus disease 2019 (COVID-19) pandemic. It begins by reviewing migration developments throughout the past 60 years. It then examines pandemic-related migration trends and policies. It concludes with a series of general observations and insights that should guide local, national, regional, and international policymakers, moving forward. In particular, it proposes the following: National measures to combat COVID-19 should include international migrants, irrespective of their legal status, and should complement regional and international responses. Localities, nations, and the international community should prioritize the safe return and reintegration of migrants. States and international agencies should plan for the gradual re-emergence of large-scale migration based on traditional push and pull forces once a COVID-19 vaccine is widely available. States should redouble their efforts to reconcile national border security concerns and the basic human rights of migrants, refugees, and asylum seekers. States and the international community should accelerate their efforts to address climate-related migration. States of origin, transit, and destination should directly address the challenges of international migration and not minimize them.

Keywords: Migration, Movement, Migrants, Refugees.

Director of research at the Center for Migration Studies, New York.

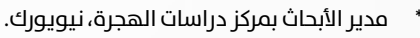

Translator at the Arab Center for Research and Policy Studies.

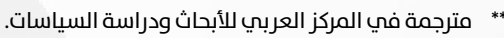

(

Joseph Chamie, "International Migration amid a World in Crisis," Journal on Migration and Human Security, vol. 8, no. 3 (2020), pp. 230-245. 


\section{مقدمة}

بعد أن شهد العالم مؤخرًا أوسع حركة لسكانه في تاريخ البشرية، ها هو اليوم في قلب أزمة كارثية مفاجئة بسبب

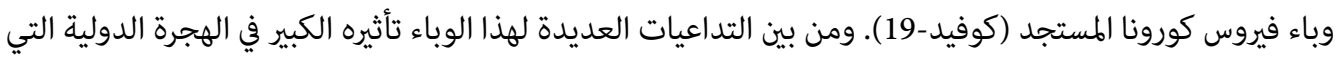
أصبحت مكونًا أساسيًا وضروريًا للاقتصاد المعولم.

سعت الحكومات في كل أنحاء العامل إلى وضع حدّ لانتشار الفيروس، فأغلقت حدودها وفرضت حظر السفر وقيّدت

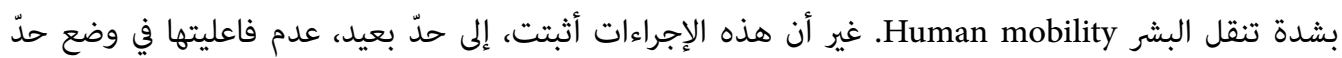
لانتشار الفيروس(1). ففي غضون أشهر، كان مرض فيروس كورونا 2019 قد تفشّى بسرعة بين البلدان وداخلها في جميع أنحاء العالم.

وبداية من منتصف عام 2020، كان قد أصيب ما لا يقل عن 12 مليون شخص بالفيروس، وتوفِّ أكثر من نصف مليون شخص بسبب فيروس كورونا (2.) وبذلك، كان لهذه الجائحة تأثير هائل في الحياة اليومية والرفاه بالنسبة إلى نحو ثانية

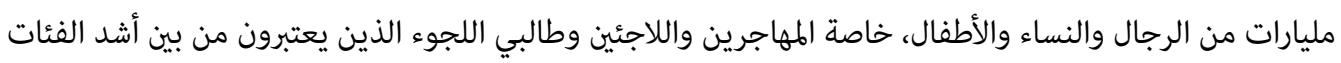
ضعفًا بسبب أوضاعهم الشخصية.

مل تقتصر آثار هذه الأزمة الصحية العالمية الجديدة على المذبحة البشرية العشوائية، والتداعيات الاقتصادية المتنامية،

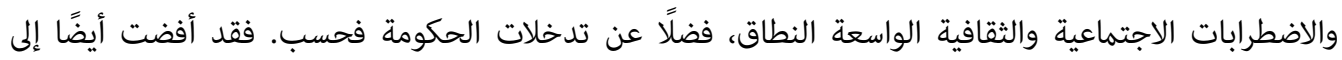

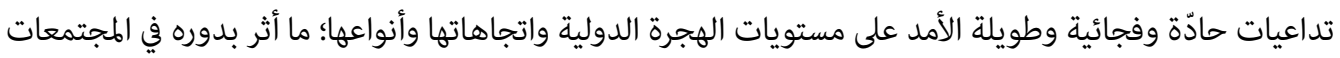
المحلية والشعوب ومئات الملايين من المهاجرين وعائلاتهم تأثيرً كبيرًا.

وقد أتت جائحة فيروس كورونا في وقت يواجه فيه العالم مجموعة من التحديات العالمية التي تؤثر، أيضًا، في التنقل البشري. وتشمل هذه التحديات التغير المناخي، والتدهور البيئي، والنمو السكاني، والفقر، والمجاعة، والنزاع المسلح، والتهجير القسري. وقد فاقمت جائحة كورونا هذه التحديات العالمية.

ومن أجل فهم حالة الهجرة الدولية في خضم الأزمة الصحية الحالية، من المفيد إجراء استعراض سريع لمستويات الهجرة الدولية واتجاهاتها وأبعادها الرئيسة في الماضي القريب. وقد تفضي هذه المراجعة لنصف القرن الماضي، مقترنة بتقييم وضع الهجرة الحالية الناجمة عن الجائحة، إلى بلورة أسسٍ سليمة قائة على المعرفة لاستباق ما يكن أن تكون ولكون عليه مستويات الهجرة الدولية المستقبلية واتجاهاتها وجوانبها المهمة.

يوفٌر استعراض ماضي الهجرة الدولية، وتقييم حاضرها، وتوقع مستقبلها، أساسًا متينًا للحكومات من شأنه أن

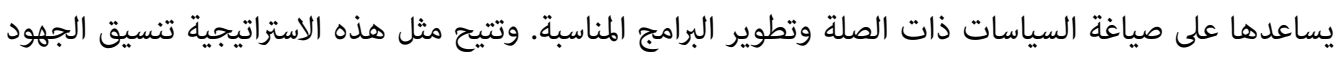
الإقليمية والدولية لععالجة الجوانب المهمة للهجرة الدولية.

1 David J. Bier, "How Travel Bans Failed to Stop the Spread of COVID-19," Cato Institute, 14/5/2020, accessed on 17/2/2021, at: https://bit.ly/37ollg3

2 الأعداد المذكورة لعدد الإصابات بفيروس كورونا، والوفيات الناجمة عنه، مأخوذة من موقع Worldometer، بدايةً من 15 توز/ يوليو 2020. يُنظر: "COVID-19 CORONAVIRUS PANDEMIC," Worldometer, 19/2/2021, accessed on 17/2/2021, at: http://bit.ly/3s0DEzN 


\section{الماضص القريب}

يُتغاضى أحيانًا عن كون الهجرة الدولية ليست بظاهرة عالمية جديدة على الإطلاق، على الرغم من الاعتراف بذلك على نطاق واسع (3). فقد شكّلت الهجرة الدولية، الطوعية والقسرية، على حد سواء، سمة دائمة وبارزة للبشرية والتغيّر الديموغرافي عبر العصور(4). ولكن طرأت في الماضي القريب، تغيّرات استثنائية في حجم الهجرة الدولية ومصادرها وأسبابها ونتائجها (5).

الشكل (1)

أعداد المهاجرين الدوليين ونسبتها المئوية من مجموع سكان العالم بين عامَي 1960 و2050 (بالملايين)

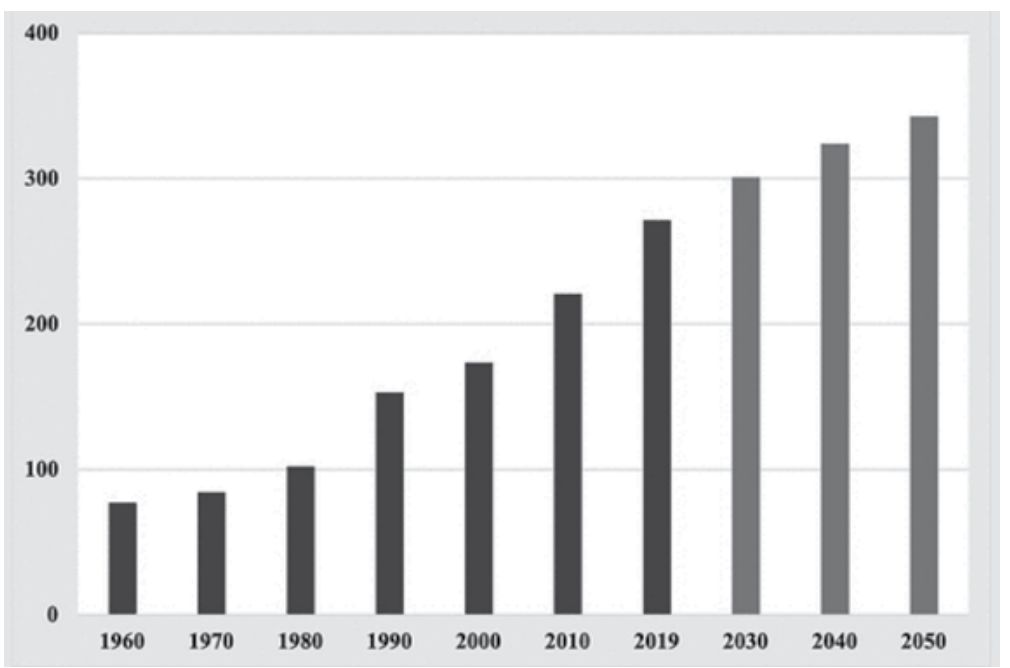

يشهد العالم أكبر حركة للسكان في تاريخ البشرية، فقد عبر الملايين من الرجال والنساء والأطفال الحدود الدولية ليستقروا في بلد آخر، وربما يهاجر العديد من املايين الآخرين إذا استطاعوا ذلك (6)، ثمّ إنّ التغيّرات الاستثنائية التي

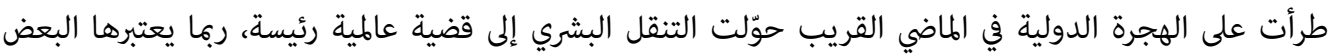
القضية الحاسمة في القرن الحادي والعشرين (7).

3 "International Migration Outlook 2019," OECD iLibrary, 2019, accessed on 17/2/2021, at: http://bit.ly/3jXAVEy

4 Carmen Boghean, "The Phenomenon of Migration: Opportunities and Challenges," USV Annals of Economics and Public Administration, vol. 16, no. 3 (2016), pp. 14-20, accessed on 17/2/2021, at: https://bit.ly/3rVYRe4

5 Stephen Castles, Hein de Haas \& Mark J. Miller, Age of Migration: International Population Movements in the Modern World, $5^{\text {th }}$ ed. (London: Palgrave Press, 2014).

6 Neli Esipova, Anita Pugliese \& Julie Ray, "More than750 Million Worldwide Would Migrate if They Could," Gallup News, 10/12/2018, accessed on 17/2/2021, at: http://bit.ly/37ltiTj

$7 \quad$ Alexander Betts, "Human Migration will be a Defining Issue of this Century: How Best to Cope?" The Guardian, 20/9/2015, accessed on 17/2/2021, at: http://bit.ly/3s3ZvXk 
انعكست الهجرة الدولية على التنمية الاجتماعية والاقتصادية في كل المناطق الرئيسة في العالم. وقد أدت تأثيراتها إلى نشوء جدال عام، وسَنْ تشريعات، وإجراء تدخلات حكومية، وتوقيع عدد من الاتفاقيات الدولية، وعمليات استجابة

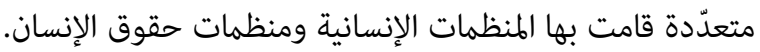

تزامن النمو السريع غير المسبوق لسكان العالم في أعقاب الحرب العالمية الثانية، مع ارتفاع في عدد المهاجرين

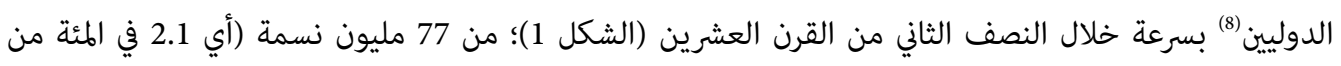
مجموع سكان العام) في عام 1960 إلى 174 مليون نسمة (أي 2.8 في المئة من سكان العالم) أثناء نهاية القرن العشرين.

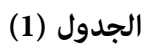

* المهاجرون الدوليون واللاجئون وسكان العالم والنسبة المئوية (1960-، (1950)

\begin{tabular}{|c|c|c|c|c|c|}
\hline للمهاجرين اللاجئين النسئ & $\begin{array}{c}\text { مجموع اللاجئين } \\
\text { (بالملايين) }\end{array}$ & اللمهاجر المئوية & $\begin{array}{c}\text { المهاجرون الدوليون } \\
\text { (باكلاينين) }\end{array}$ & 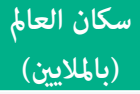 & العام \\
\hline$\% 2.1$ & 2 & $\% 2.5$ & 77 & 3,035 & 1960 \\
\hline$\% 2.9$ & 2 & $\% 2.3$ & 84 & 3,700 & 1970 \\
\hline$\% 8.3$ & 8 & $\% 2.3$ & 102 & 4,458 & 1980 \\
\hline$\% 11.4$ & 17 & $\% 2.9$ & 153 & 5,327 & 1990 \\
\hline$\% 7.0$ & 12 & $\% 2.8$ & 174 & 6,143 & 2000 \\
\hline$\% 4.8$ & 11 & $\% 3.2$ & 221 & 6,957 & 2010 \\
\hline$\% 9.5$ & 26 & $\% 3.5$ & 272 & 7,713 & 2019 \\
\hline$\% 9.5$ & 29 & $\% 3.5$ & 301 & 8,548 & 2030 \\
\hline$\% 9.5$ & 31 & $\% 3.5$ & 324 & 9,199 & 2040 \\
\hline$\% 9.5$ & 33 & $\% 3.5$ & 343 & 9,735 & 2050 \\
\hline
\end{tabular}

* تفترض التوقعات أن نسب أعداد المهاجرين واللاجئين لعام 2019 ستبقى ثابتة.

في عام 2019، بلغ عدد الأشخاص المقيمين خارج بلدهم الأم 272 مليون نسمة؛ أي نحو 3.5 في المئة من سكان العالم،

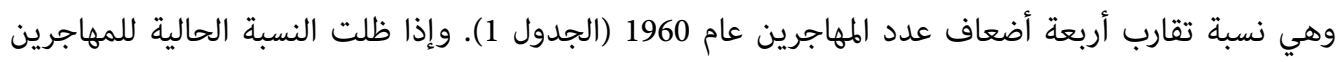

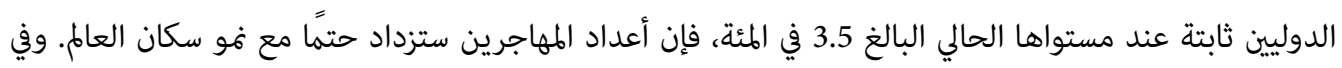

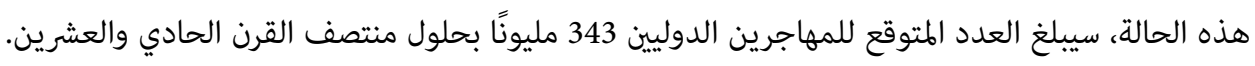
تسكن أغلبية المهاجرين الدوليين (272 مليون شخص)، في الوقت الراهن، أي ما يقارب 60 في المئة، في المناطق الأكثر

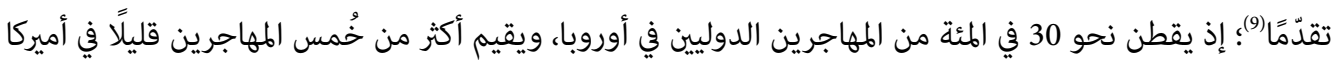

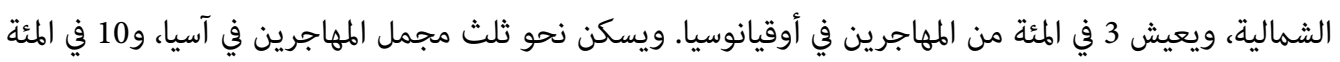
منهم في أفريقيا، و4 في المئة في أميركا اللاتينية وجزر البحر الكين في الكاريبي.

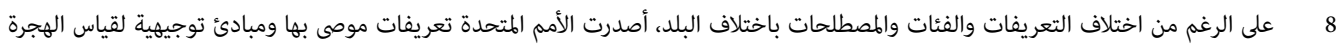

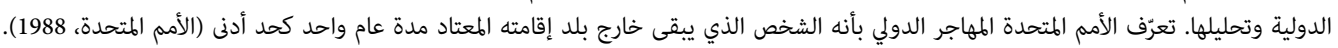

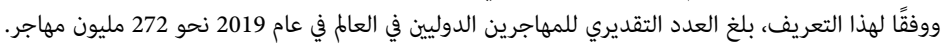

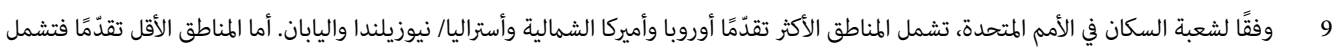

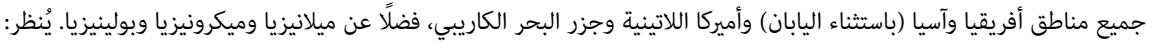
United Nation, Department of Economic and Social Affairs Population Dynamics, "Population Division: World Population Prospects 2019, Definition of Regions," accessed on 19/2/2021, at: https://bit.ly/2NbNqQM 
أقام نصف الههاجرين في العالم في عشر دول. فالولايات المتحدة الأميركية استضافت 51 مليون مهاجر، وهو العدد الأكبر بين جميع البلدان الأخرى. أما أمانيا والمملكة العربية السعودية، فاستضافتا ثاني وثالث أكبر عدد من المهاجرين الدوليين في العالم (نحو 13 مليون مهاجر في كل من البلدين)، تليهما روسيا التي استقبلت 12 مليون مهاجر، والمملكة المتحدة التي استقبلت 10 ملايين مهاجر (الشكل 2).

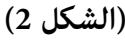

أعداد الههاجرين الدوليين في قائمة البلدان العشرة الأولى المستقبلة للمهاجرين عام 2019 (بالملايين)

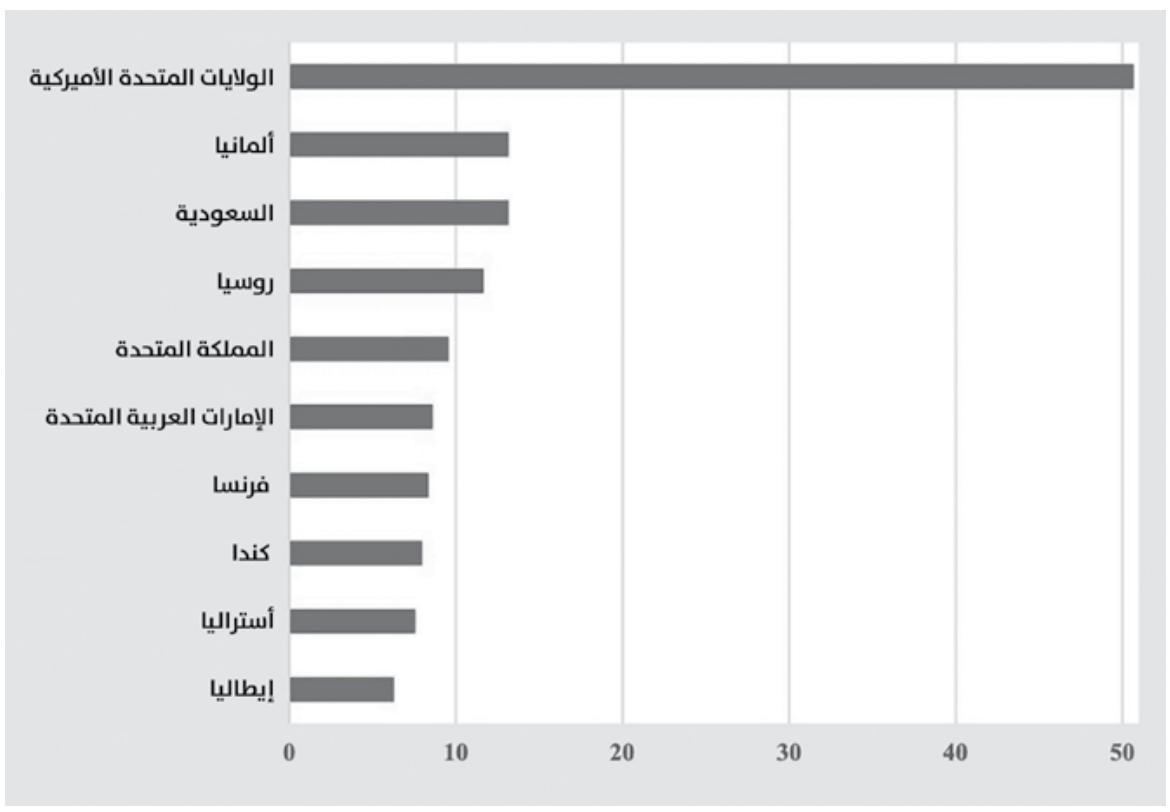

يتحدّر المهاجرون الدوليون من عدد كبير من البلدان المرسلة. وقد استحوذت الدول العشر الأولى المرسلة في عام

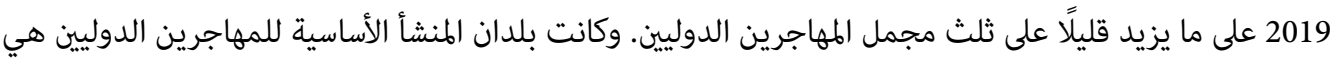
الهند (18 مليون مهاجر)، تليها المكسيك (12 مليون مهاجر)، فالصين (11 مليون مهاجر)، فروسيا (10 ملايين مهاجر)، فسورية (8.2 ملايين مهاجر) (الشكل 3). إضافة إلى النمو السريع الذي شهدته الهجرة الدولية، طرأت خلال النصف الأخير من القرن الماضي زيادة سريعة

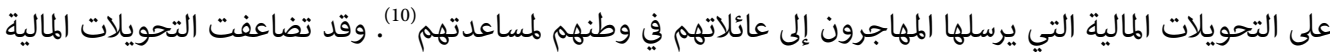
السنوية من عدة مليارات من الدولارات الأميركية في عام 1970 لتتجاوز 700 مليار دولار أميركي، وهو مبلغ يفوق

بكثير المساعدات الإفمائية الخارجية (الشكل 4). 
(الشكل 3)

أعداد المهاجرين الدوليين في قائمة البلدان العشرة الأولى المرسلة عام 2019 (بالملايين)

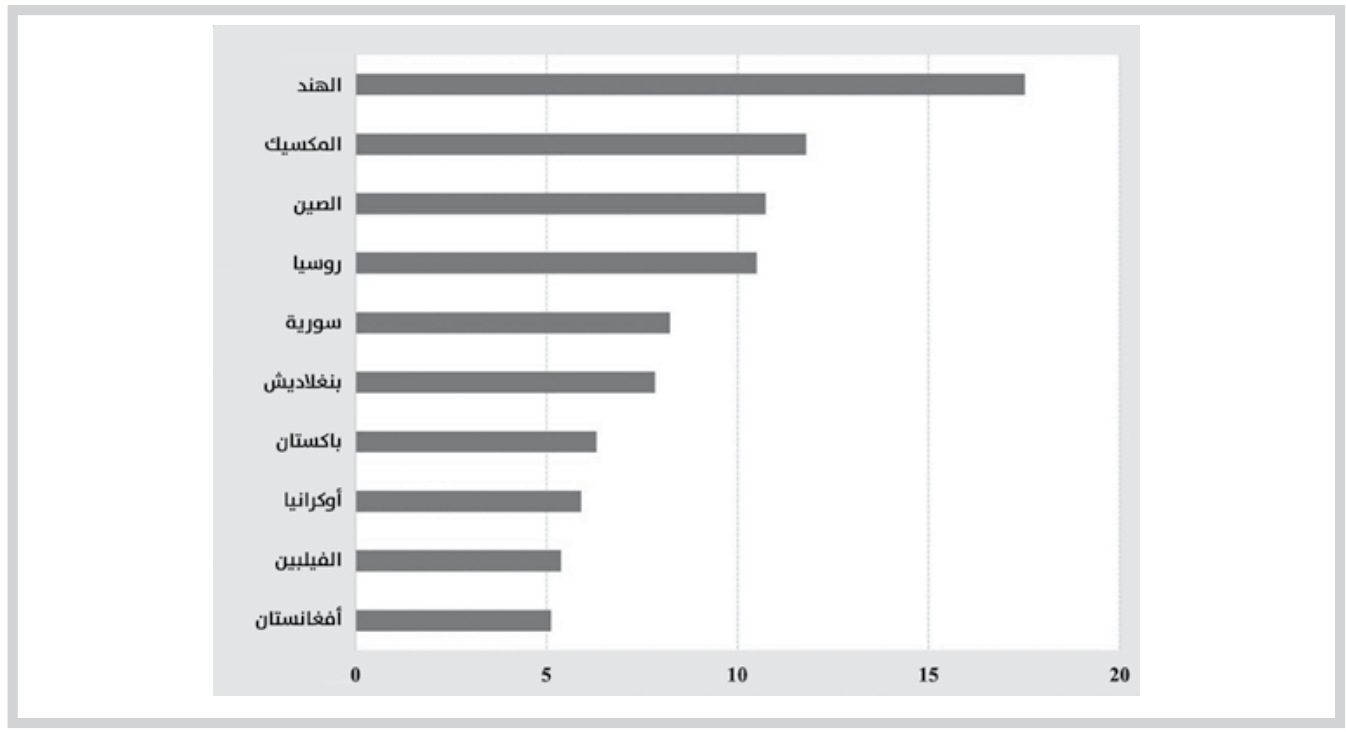

(الشكل 4)

مجموع تدفقات التحويلات المالية الواردة على نطاق العالم في الفترة 1970-2019 (بمليارات الدولارات)

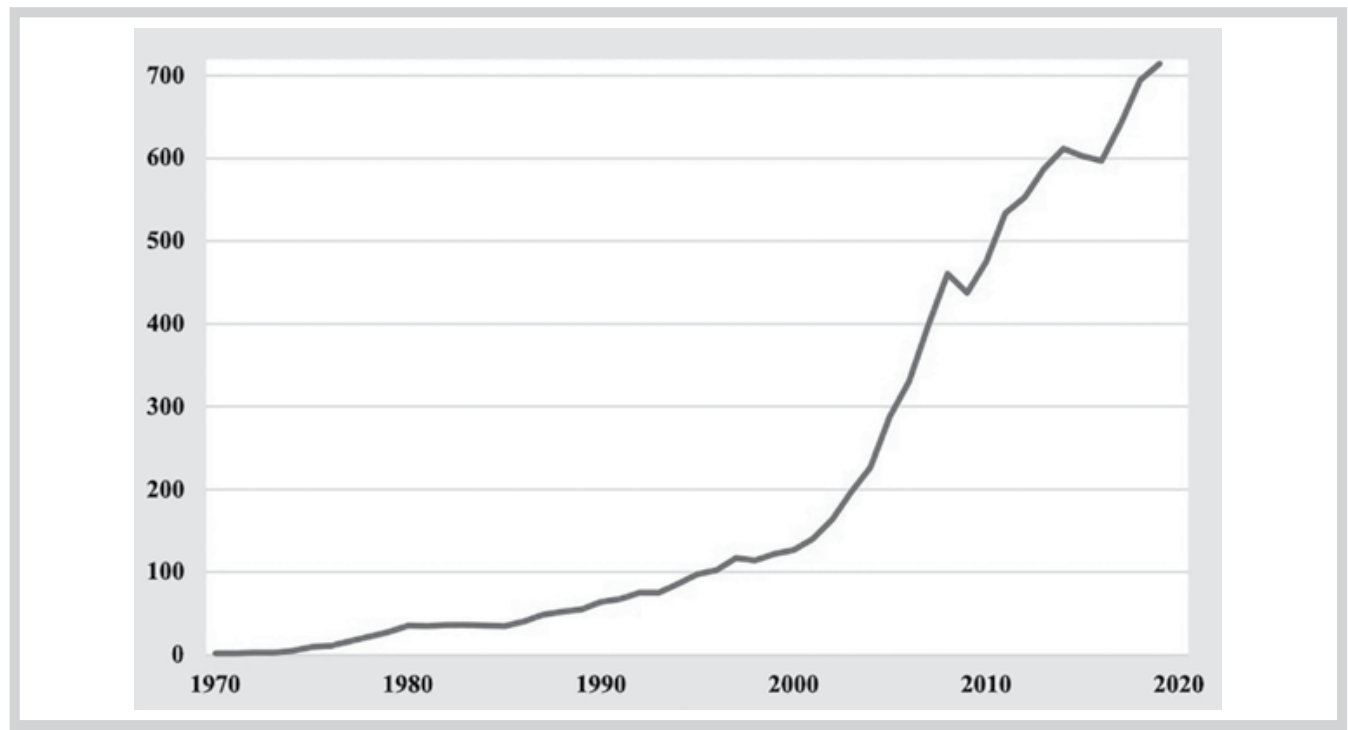


في عام 2019، تلقت الهند أكبر عدد من التحويلات المالية (83 مليار دولار)، تلتها الصين (68 مليار دولار)، فالككسيك (39 مليار دولار)، فالفلبين (35 مليار دولار)، فمصر (27 مليار دولار)(11. وتُعدّ الولايات المتحدة أكبر مَصادر تدفقات الحوالات المالية الخارجية للمهاجرين (68 مليار دولار)، تليها الإمارات العربية المتحدة (44 مليار دولار)، فالمملكة العربية السعودية (34 مليار دولار)، فسويسرا (27 مليار دولار)، فأكانيا (25 مليار دولار). تشكّل التحويلات مصدرًا رئيسًا للعملة الأجنبية للعديد من البلدان (الشكل 5). ففي هايتي، بلغت التحويلات الهالية في عام 2019، وقد وردت في معظمها من الولايات المتحدة، 37 في المئة من الناتج المحلي الإجمالي. في حين شكّلت التحويلات في جنوب السودان ثلث الناتج المحلي الإجمالي للدولة. أما في سبعة بلدان أخرى في مناطق مختلفة، فقد راوح حجم التحويلات بين خُمس ورُبع الناتج المحلي الإجمالي لتلك الدول.

(الشكل 5)

\section{التحويلات المالية بصفتها نسبة من الناتج المحلي الإجمالي عام 2019}

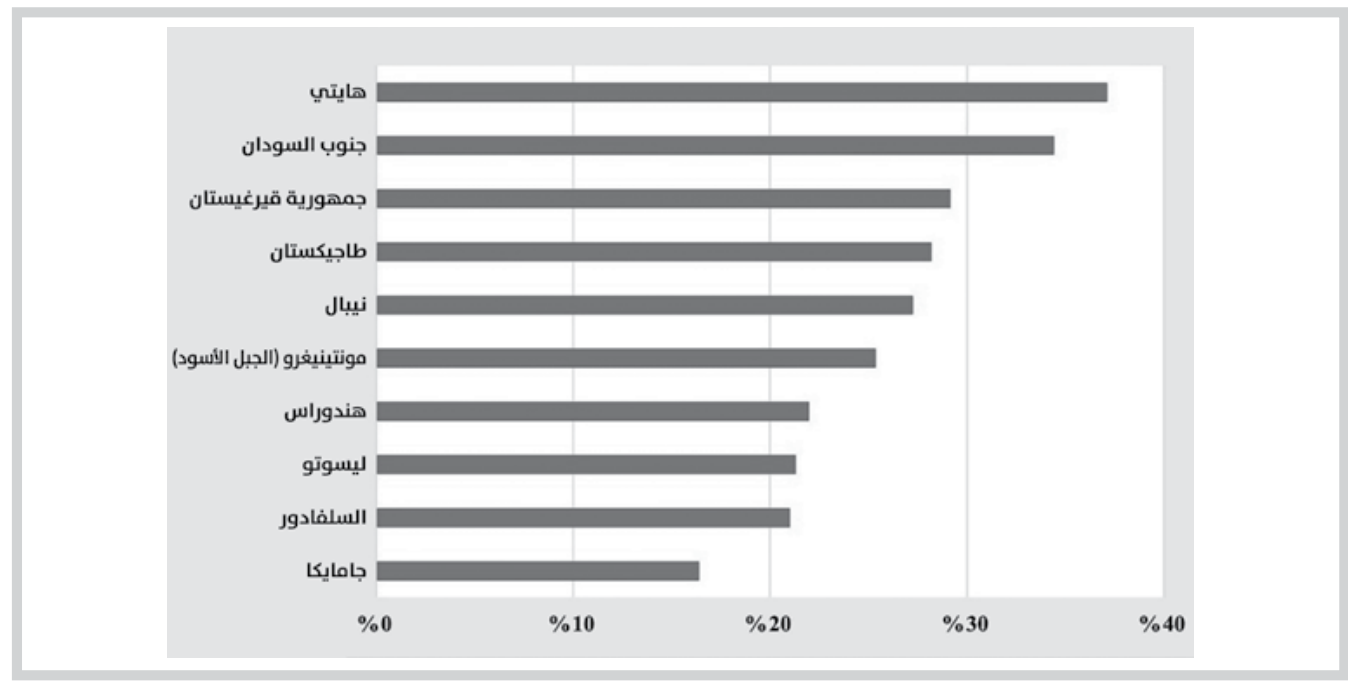

على غرار الارتفاع السريع في أعداد المهاجرين الدوليين، ارتفع عدد اللاجئين في جميع أنحاء العالم ارتفاعًا ملحوظًا في الماضي القريب. فقد بلغ العدد الإجمالي للاجئين ومُلتمسي اللجوء في نهاية عام 2019 ما يقارب 26 مليون شخص؛ أي أي أي بزيادة نحو 13 مليون شخص منذ عام 2010 (الشكل 6).

ينضوي نحو 20 مليون لاجئ تحت لواء المفوضية السامية للأمم المتحدة لشؤون اللاجئين Office of the United Nations High Commissioner for Refugees UNHCR

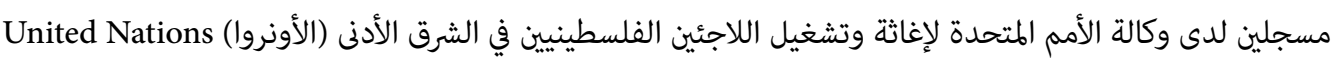


Relief and Works Agency for Palestine Refugees in the Near East, UNRWA هناك أكثر من 4 ملايين شخص من طالبي اللجوء، بمن فيهم 800 ألف فنزويلي. ويُقدّر أنّ 4.5 ملايين شخص فرّوا

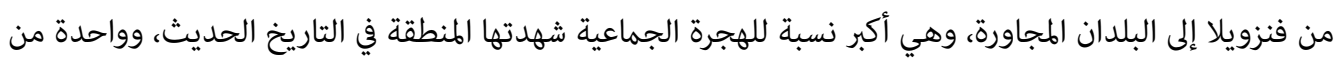

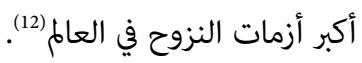

\section{(الشكل 6) - (ال)}

أعداد اللاجئين على نطاق العالم بين عامي 1960 و2050 (بالملايين)

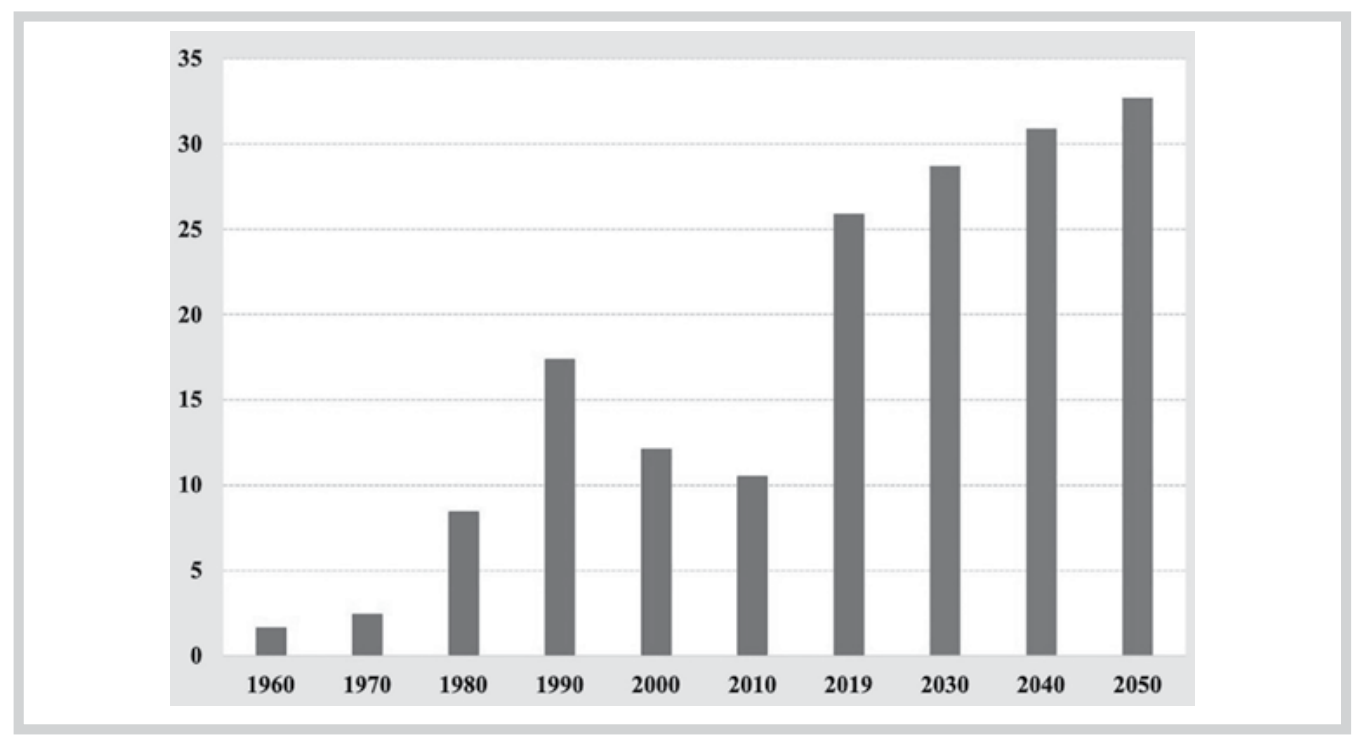

ينحدر نحو 80 في المئة من النازحين عبر الحدود الدولية من عشرة بلدان (الشكل 7)، خمسة منها (أفغانستان،

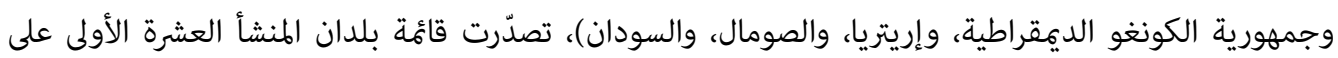
مدار العقد الماضي.

منذ عام 2014، أصبحت سورية بلد المنشأ الرئيس للاجئين؛ إذ تستقبل 126 دولة نحو 7 ملايين لاجئ سوري. ويوجد

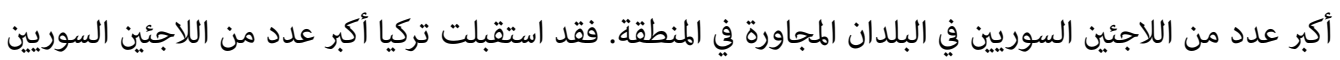

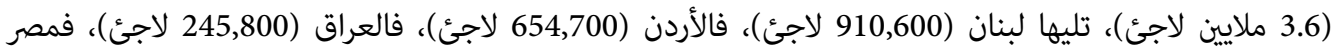

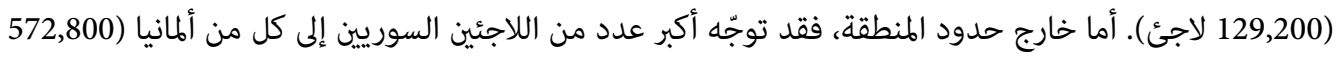

$$
\text { لاجئ)، والسويد (113,400 لاجئ). }
$$

استضافت عشرة بلدان نحو 60 في المئة من النازحين عبر الحدود الدولية. وتُعدّ تسعة بلدان، من هذه البلدان العشرة

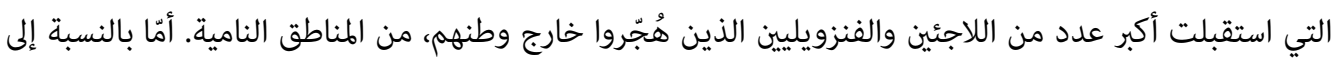

12 United Nations High Commissioner for Refugees (UNHCR), "Global Trends: Forced Displacement in 2019," accessed on 17/2/2021, at: https://bit.ly/3jY9zhB 
أولئك الهاربين من النزاع والاضطهاد، فيشكّل التقارب الجغرافي عاملًا مهًَّا في تحديد البلد الذي سيستقبلهم، حيث

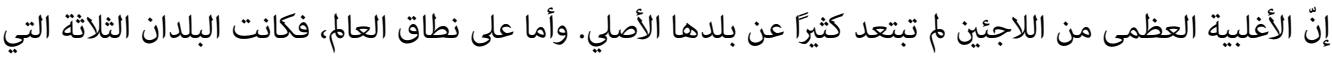

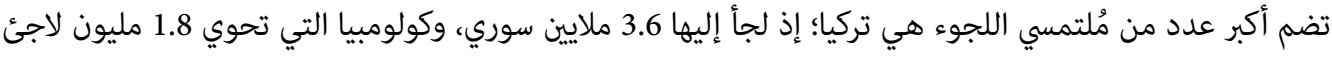

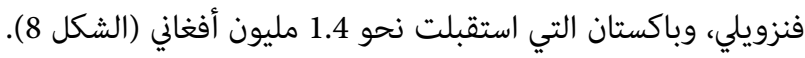

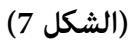

أعداد اللاجئين بحسب بلد المنشأ عام 2019 (بالهلايين)

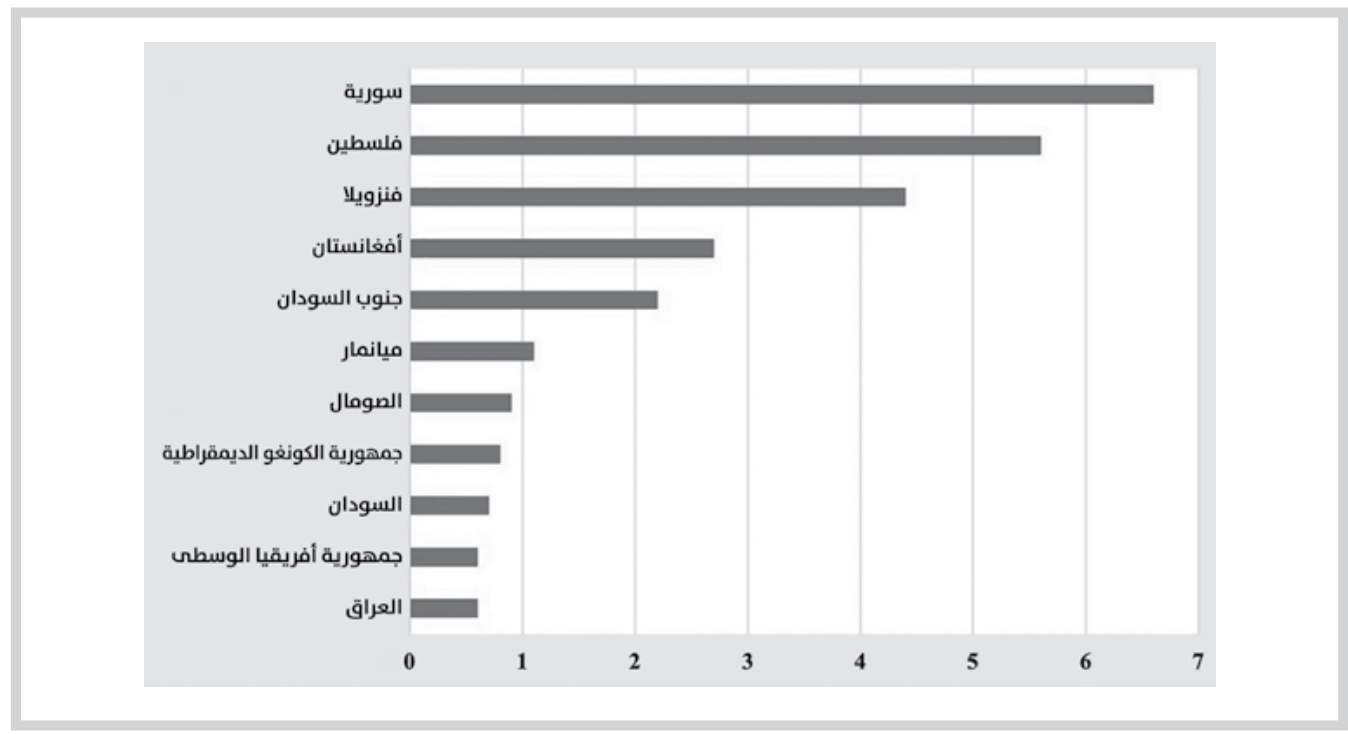

(الشكل 8)

أعداد اللاجئين بحسب البلد المضيف عام 2019 (بالملايين)

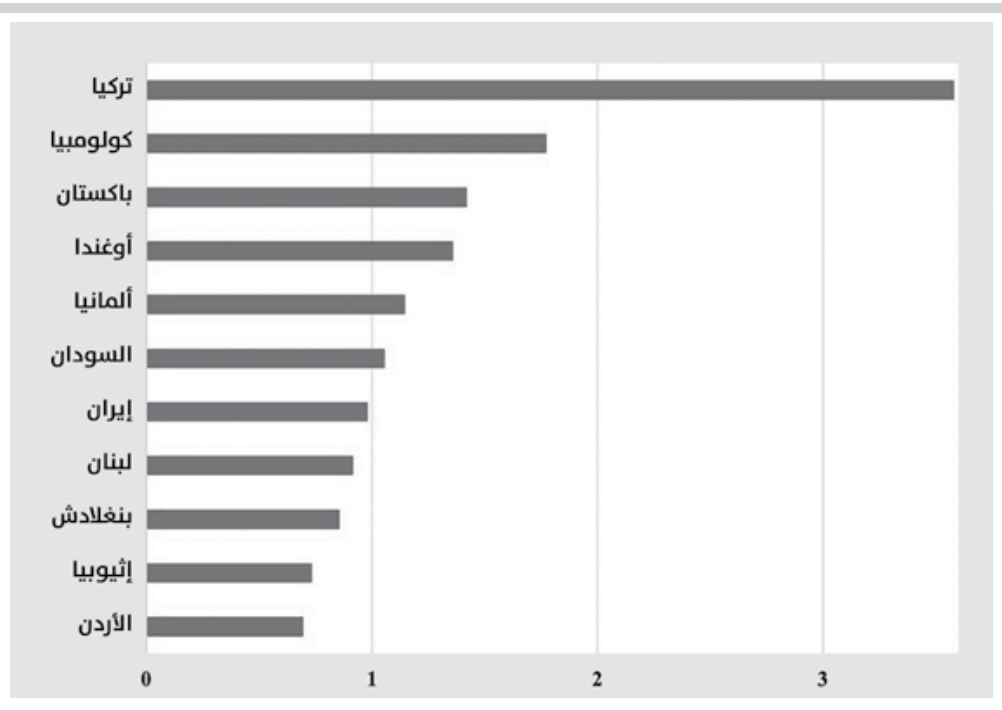


يبرز تحدًّ آخر مهم، على الصعيد العالمي، وهو الهجرة غير الشرعية. فغالبًا ما يجازف الملايين من الرجال والنساء والأطفال بحياتهم، وهم الذين لا تتوافر لديهم فرصة الهجرة عبر السبل القانونية إلى بلدان أخرى، من أجل الوصول إلى بلد آخر والاستقرار فيه، ولا سيما في المناطق الأكثر تطورًا. ويكمن أحد الأسباب الأساسية وراء الهجرة غير الشرعية في أن الطلب على المهاجرين في البلدان المستقبلة لهم أقل كثيرًا من العدد المتوافر من المهاجرين المحتملين الراغبين

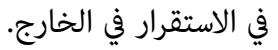

وغالبًا ما يرتبط التهريب والاتجار بالبشر ارتباطًا وثيقًا بالهجرة غير الشرعية. فبسبب الطلب على اليد العاملة الرخيصة والطوعية والاستغلال الجنسي وما يرافق ذلك من مخاطر قليلة وأرباح كبيرة، تزداد أنشطة الجماعات الإجرامية في مجال التهريب والاتجار بالبشر في كل منطقة من مناطق العالم تقريبًا. ونتيجة لذلك، تقع أعداد متنامية من الرجال والنساء والأطفال ضحايا لأساليب الخداع وسوء المعاملة؛ بما في ذلك عبودية الدَّيْن، والتعذيب، والاحتجاز غير القانوني، والاعتداء الجنسي، والاغتصاب، والتهديد، إضافة إلى استخدام العنف ضدهم وضد عائلاتهم وأصدقائهم (13.). في السنوات الأخيرة، شكّلت تدفقات الهجرة الدولية، بخاصة الهجرة غير الشرعية، تحدّيًا مهمًا لقدرات السلطات الحكومية والمنظمات الدولية الحكومية، ولأوضاعها المالية، وللموقف العامّ تجاه المهاجرين. لذلك، تبنّت الحكومات، في كل منطقة تقريبًا، سياسات للحد من الهجرة الدولية، وتقييد مستويات تدفقاتها وتكوينها، وخفض تدفقات اللاجئين، ورفض استقبال طالبي اللجوء، وإعادة أولئك المقيمين بصفة غير قانونية إلى أوطانهم، وإعادة تحديد الجنسية أو رفض منحها لمجموعات معينة

على المستوى الحكومي الدولي، صدّقت أغلبية كبيرة من الدول الأعضاء في الأمم المتحدة على اتفاقين عالميين، في كانون الأول/ ديسمبر 2018؛ إذ يتعلّق الاتفاق الأول بالهجرة الدولية، في حين يرتبط الثاني باللاجئين(15). أما البلدان التي صوّتت بشكل جمْعي لمصلحة الاتفاق العالمي من أجل الهجرة الآمنة والمنظمة والنظامية (16) فقد استضافت نحو 181 مليون مهاجر دولي في عام 2019؛ أي بنسبة 67 في المئة من العدد الإجمالي العالمي للمهاجرين (17). وأما

13 Joseph Chamie, "Human Trafficking in the $21^{\text {st }}$ Century," Foreign Policy Association, Great Decisions, 2015 Briefing Book, accessed on 17/2/2021, at: http://bit.ly/3s0ZvHh

14

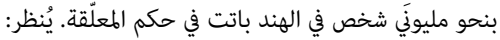
Suhasini Raj \& Jeffrey Gettleman, "A Mass Citizenship Check in India Leaves 2 Million People in Limbo," The New York Times, 31/8/2019, accessed on 17/2/2021, at: http://nyti.ms/3jYHUwM

15 فضلًا عن الاتفاق العالمي من أجل الهجرة الآمنة والمنظمة والنظامية (2018)، والاتفاق العالمي بشأن اللاجئين (2018)، تشمل اتفاقيات حكومية دولية

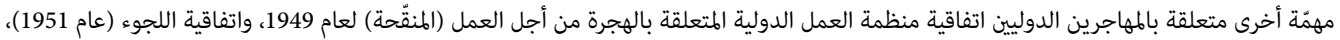

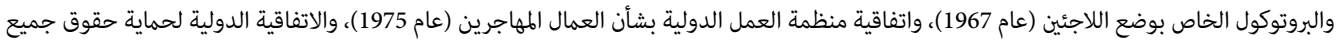
العمال المهاجرين وأفراد أسرهم (عام 1990)، وبروتوكول مكافحة تهريب المهاجرين (عام 2000)، وبروتوكول منع الاتجار بالبشر (عام 2000).

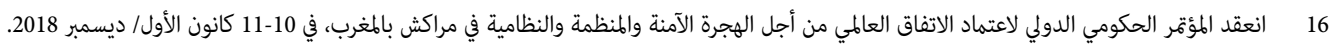
United Nations, General Assembly, "Draft Outcome Document of the Conference," 2018, accessed on 19/2/2021, at: http://bit.ly/2NC6c3z

17 Kevin J. Appleby, "Implementation of the Global Compact on Safe, Orderly, and Regular Migration: A Whole-of-Society Approach," Journal on Migration and Human Security, vol. 8, no. 2 (2020), pp. 214-229. 
البلدان التي صوتت لمصلحة الاتفاق العالمي بشأن اللاجئين (18)، فقد استقبلت نحو 25 مليون لاجئ (89 في المئة من

$$
\text { العدد الإجمالي للاجئين في العالم). }
$$

في أواخر عام 2019، صدّق أكثر من ثلاثة أرباع الدول الأعضاء في الأمم المتحدة على الوثائق التي تهدف إلى حماية اللاجئين أو مكافحة تهريب المهاجرين والاتجار بالبشر. وفي المقابل، صدّق أقل من 30 في المئة من الدول على الوثائق التي تحمي حقوق العمّال المهاجرين.

\section{الحاضر}

لقد تسبب تفشي فيروس كورونا، الذي يُعتقد أنه انطلق من مدينة ووهان الصينية في أواخر عام 2019، بأزمة صحية World Health Organisation عالمية غير مسبوقة. وبحلول منتصف آذار/ مارس، أعلنت منظمة الصحة العالمية المرضَ وباءً عاطيًّا. وفي تلك الفترة، كانت دول عديدة في جميع أنحاء العالم قد اتخذت قرار إغلاق حدودها؛ إذ اعتقدت الحكومات أن وضع قيود على السفر سيحد من انتشار الفيروس.

وبحلول نيسان/ أبريل، كان يقيم ما لا يقل عن 90 في المئة من سكان العالم (نحو 7.1 مليارات شخص)، في بلدان فرضت قيودًا على الوافدين من بلدان أخرى، بمن في ذلك السياح والهسافرون من رجال الأعمال والطلاب والهاجرون الجدد(19). كما فرضت العديد من الدول فترة حجر صحي ذاتي، يدوم في العادة 14 يومًا، بالنسبة إلى من يُسمح لهم من مئم

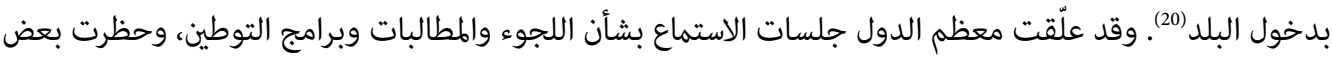
الدول دخول طالبي اللجوء.

في نيسان/ أبريل، أصبحت الولايات المتحدة، بعد أن فَرضت قيودًا إضافية لمواجهة الفيروس، الدولةَ الأولى التي برّرت صراحة القيود على حرية التنقل؛ لا من باب المخاطر الصحية التي قد تسبّبها، بل لحماية الوظائف والرفاه الاقتصادي

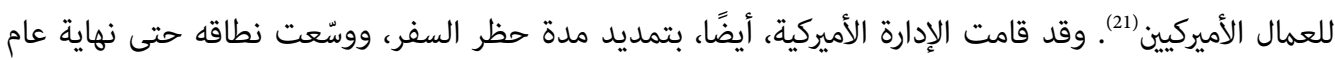
2020؛ ما يجعل من سياستها الحالية بشأن الحظر على الهجرة في التاريخ الأميركي السياسةَ الأكثر شمولًا (22.).

18

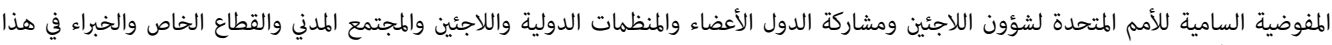

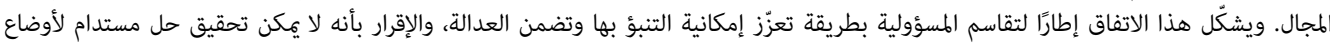

اللاجئين من دون تعاون دولي. United Nations, Report of The United Nations High Commissioner for Refugees, Global Compact on Refugees (New York: 2018), accessed on 19/2/2021, at: https://bit.ly/2LYQ4cd

19 Phillip Connor, "More than Nine-in-Ten People Worldwide Live in Countries with Travel Restrictions amid Covid-19," Pew Research Center, 1/4/2020, accessed on 17/2/2021, at: http://pewrsr.ch/2ZmH5V5

20 "Managing International Migration under COVID-19," OECD, 10/6/2020, accessed on 17/2/2021, at: https://bit.ly/3qG0Oeo

21 Muzaffar Chishti \& Sarah Pierce, "The U.S. Stands Alone in Explicitly Basing Coronavirus-Linked Immigration Restrictions on Economic Grounds," Migration Information Source, Migration Policy Institute (2020).

22 Ilya Somin, "The Danger of America's Coronavirus Immigration Bans," The Atlantic, 28/6/2020, accessed on 17/2/2021, at: http://bit.ly/3qvnRbM 
عارض العديد من رجال الأعمال قيود السفر الأميركية الجديدة التي تحد من عملية استيراد العمالة الأجنبية وتعلّق

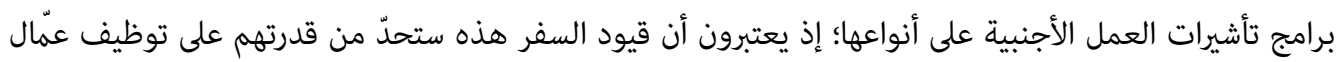

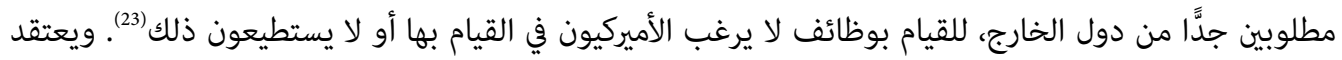
البعض أن الإدارة الأميركية استغلت الخطر الذي قد يسببه فيروس كورونا على الصحة العامة ذريعةً لإصدار سلسلة

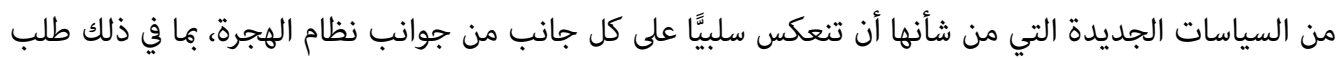
اللجوء والهجرة والحصول على الجنسية (24).

ونتيجة لحظر السفر والقيود المفروضة على التنقل، توقفت حركة الأشخاص عبر الحدود الدولية توقفًا كليًّا. وبهذا

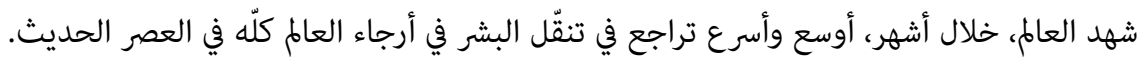
وبعد إغلاق الدول حدودها، بدأت في اتخاذ إجراءات إضافية للحد من انتشار الفيروس. وشملت هذه الإجراءات الإغلاق الاقتصادي، والاحتماء داخل المنازل Sheltering-in-place، وإغلاق المدارس، والعزلة الاجتماعية. وكان للتداعيات الاقتصادية والاجتماعية والسياسية، من جرّاء تلك التدابير وما يرتبط بها، عواقب اقتصادية مباشرة ووخيمة بالنسبة إلى البلدان المرسلة للمهاجرين، وفاقمت من حدّة الظروف ومواطن الضعف التي يعانيها العديد من المهاجرين وأُسرهم ومجتمعاتهم.

مل يقتصر الأمر على عدم قدرة العمال المهاجرين على السفر بحثًا عن عمل فحسب، بل عاد العديد منهم إلى بلدهم الأصلي. غير أن بعض العمّال المهاجرين قد علقوا في الخارج وباتوا غير قادرين على العودة إلى بلدهم الأم بسبب إغلاق الحدود والقيود المفروضة على السفر. لقد أدى الوباء والخوف من الغريب أو الأجنبي إلى تعديل

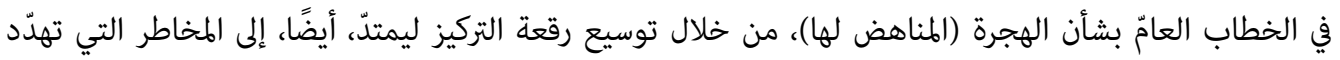
الأمن الفردي الصحي.

إنّ ظروف المعيشة والعمل جعلت المهاجرين الدوليين أكثر عرضة للإصابة بفيروس كوفيد-19. وفي بعض الأماكن، غصّت الملاجئ والمخيمات وغرف الفنادق المكتظة بالمهاجرين العالقين. ومن ثم، مل يكن في استطاعة المهاجرين ممارسة التباعد الاجتماعي أو حماية أنفسهم من العدوى بسهولة (25). في أيار/ مايو، دعت شبكة الأمم المتحدة المعنية بالهجرة ومنظمة هيومن رايتس ووتش، غير الحكومية، Human Rights Watch

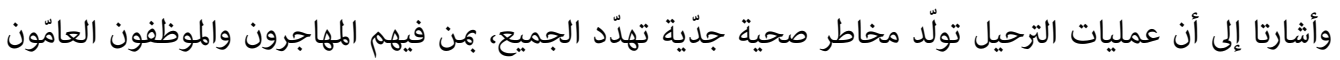
والعاملون في قطاع الصحة والمرشدون الاجتماعيون في كل من البلدان المضيفة وبلدان المنشأ.

23 Michael D. Shear \& Miriam Jordan, "Trump Suspends Visas Allowing Hundreds of Thousands of Foreigners to Work in the U.S.," The New York Times, 22/6/2020, accessed on 17/2/2021, at: http://nyti.ms/3qtHyRf

24 Jack Herrera \& Quito Tsui, "Could Covid-19 Mean the End of Asylum Law in the United States?" The Nation, 3/6/2020, accessed on 17/2/2021, at: http://bit.ly/3bcJreR

25 Weiyi Cai \& K.K. Rebecca Lai, "Packed with Migrant Workers, Dormitories Fuel Coronavirus in Singapore," The New York Times, 28/4/2020, accessed on 17/2/2021, at: http://nyti.ms/2ZoM5IV 
وعلى الرغم من أن المهاجرين قد يكونون أصغر سنَّا من السكان المحليين، فإنهم يميلون إلى العيش والعمل في أماكن

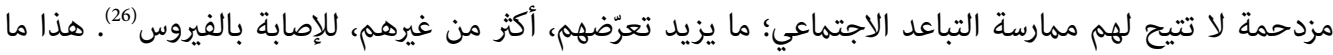

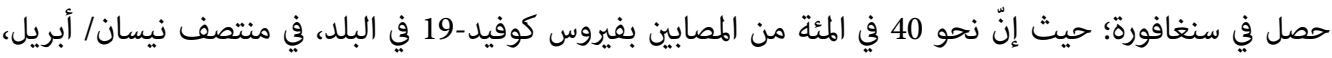
كانوا من العمال الأجانب ذوي المهارات المنخفضة، وفي المملكة العربية السعودية أيضًا؛ حيث كان أكثر من نصف المصابين من الأجانب.

كذلك، ينعكس الوضع الاجتماعي والاقتصادي للمهاجرين سلبيًّا على قدرتهم على اتخاذ جميع التدابير الاحترازية

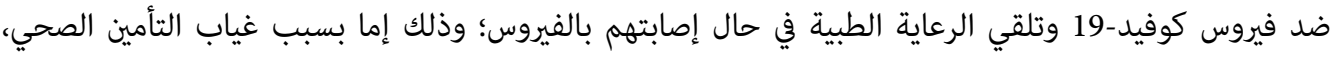

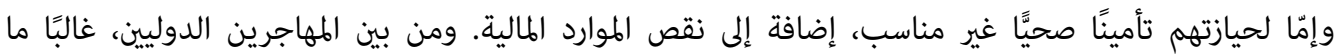

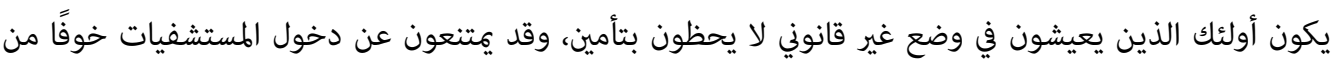
الإبلاغ عنهم وترحيلهم.

في بعض البلدان، تمّ توسيع الخدمات العامة لتشمل المهاجرين غير المسجّلين. وفي أجزاء أخرى من العالم، أربكت

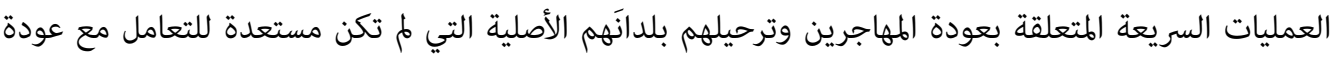
الوافدين المفاجئة، والتي حصلت أحيانًا على نطاق واسع. على سبيل المثال، كانت الولايات المتحدة، التي تعاني أكبر عدد الإصابات بفيروس كورونا في العالم، تنشر الوباء خارج حدودها من خلال الاستمرار في ترحيل آلاف المهاجرين

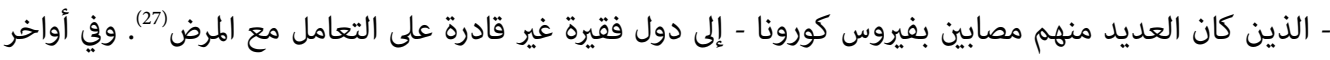

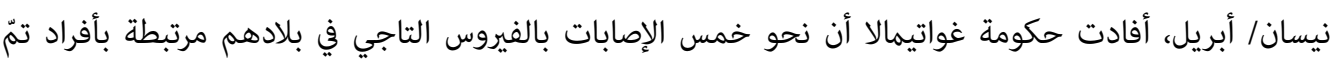

$$
\text { ترحيلهم من الولايات المتحدة (28). }
$$

أدت كلّ من الانكماشات الاقتصادية وفقدان المهاجرين لوظائفهم في الاقتصادات الرئيسة في العام إلى انخفاض حادّ

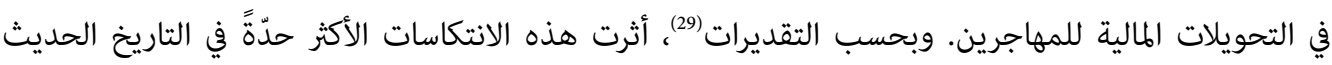

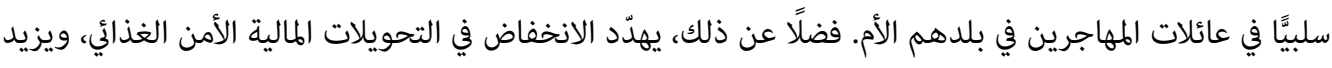
مستويات الفقر في العديد من البلدان المرسلة للمهاجرين، حيث تعتمد نسبة كبيرة من ناتجها المحلي الإجمالي على تحويلات الكهاجرين.

أفاد البنك الدولي، في هذا السياق، أن الوباء وإغلاق الدول الغنية اقتصادها التي تعتمد عليه العديد من الدول

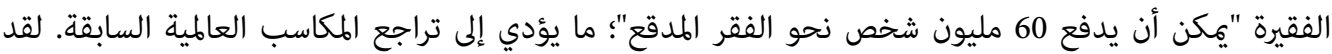

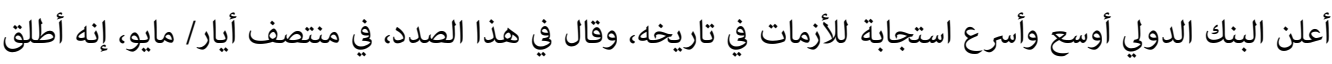

26 Hans Henri P. Kluge et al., "Refugee and Migrant Health in the COVID-19 Response," The Lancet, vol. 395 , no. 10232 (2020), pp. 1237-1239, accessed on 17/2/2021, at: https://bit.ly/3pstoii

27 Editorial Board, "Why is the United States Exporting Coronavirus?" The New York Times, 18/6/2020, accessed on 17/2/2021, at: http://nyti.ms/37mSMzP

28 Camilo Montoya-Galvez, "Exporting the Virus: Migrants Deported by U.S. Make Up 20\% of Guatemala's Coronavirus Cases," CBS News, 27/4/2020.

29 World Bank, "World Bank Predicts Sharpest Decline of Remittances in Recent History," 22/4/2020, accessed on 17/2/2021, at: http://bit.ly/3ua2bVc 
عمليات طارئة لدعم 100 دولة تضم 70 في المئة من سكان العالم البالغ عددهم 7.8 مليارات نسمة بمساعدات مالية قيمتها 160 مليار دولار (30).

أدت الجائحة إلى تفاقم مكامن الضعف الموجودة أصلًا لدى اللاجئين والمشرّدين داخليًّا على المستوى العالمي. ولقد توقفت عملية إعادة توطين اللاجئين لأسباب واقعية بسبب القيود المفروضة على السفر. علاوة على ذلك، الكان. كانت الأوضاع المعيشية لأولئك الذين يعيشون في مخيمات اللاجئين مصدر قلق طوال عقود عدة قبل أزمة جائحة كوفيد-19. فانتشار الجائحة وتداعياتها تُعرّض حياة هؤلاء الأشخاص ورفاههم لخطر متزايد.

يواجه المهاجرون الذين يعيشون في مخيمات على أعتاب أوروبا أو الولايات المتحدة احتمال تفشي الفيروس على

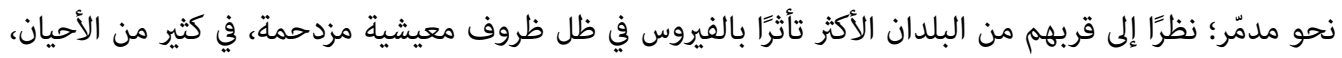

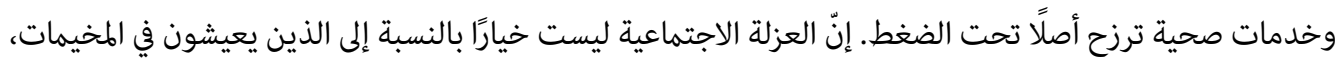
حيث لا يزال الوصول إلى المياه والصرف الصحي يشكّل تحديًا كبيرًا.

غير أن القيود المفروضة على السفر بسبب الجائحة مل تحدّ من حركة الأشخاص الفارّين من مناطق النزاع والعنف، أو الهاربين من شظف أوضاع معيشية غير إنسانية. فكثير من الأشخاص الذين يختارون مغادرة بلدهم الأم لا يسعون بالضرورة إلى وظيفة مضمونة، بل إنهم يهربون بعيدًا من مناطق النزاع والفقر.

مع استمرار انهيار الاقتصادات الذي يؤدي إلى استشراء الفقر ونقص الغذاء والشعور باليأس، قد تزداد رغبة الأشخاص الأكثر احتياجًا في تغيير مكان العيش مرة أخرى؛ ما سيزيد من عمليات التهريب. فعلى سبيل المثال، يستمر تهريب المهاجرين على طول ساحل غرب البحر الأبيض المتوسط ووسطه، لأسباب ليس أقلها استمرار النزاعات والعنف في المنطقة (31).

في بعض البلدان، أسفر إغلاق الحدود، وتدابير إغلاق البلد أيضًا، إلى تعزيز النزعة القومية والانعزالية المتطرفة؛ ما

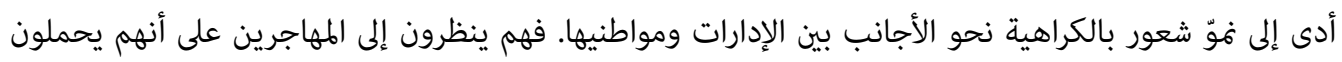
فيروس كورونا ويساهمون في انتشاره بين المجتمعات.

ولقد سعى بعض القادة الشعبويين إلى تأجيج مسألة الأمن الصحي واستغلالها(32. فعلى سبيل المثال، قال رئيس

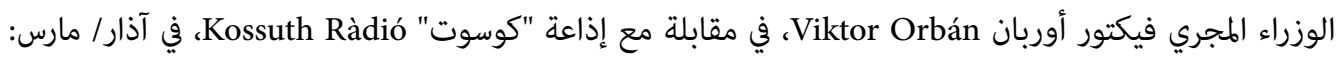
"نرى أن الفيروس جاء به الأجانب خصوصًا وهو ينتشر في صفوفهم" (33رئ.

30 World Bank, "World Bank Group: 100 Countries Get Support in Response to COVID-19 (Coronavirus)," 19/5/2020, accessed on 17/2/2021, at: http://bit.ly/2LY6xxb

31 United Nations Office for Drugs and Crime (UNODC), COVID-19 Measures Likely to Lead to an Increase in Migrant Smuggling and Human Trafficking in Longer Term, UNODC Report Finds, 14/5/2020, accessed on 17/2/2021, at: https://bit.ly/3qw37Rj

32 Ylenia Gostoli, "How European Populists Are Using Coronavirus as a Political Tool," Aljazeera, 3/3/2020, accessed on 17/2/2021, at: http://bit.ly/3jXqjFR 


\section{المستقبل القريب}

مع إغلاق أغلبية الحدود وفرض الحكومات القيود على حركة الدخول إليها من الخارج، يبدو أن الفيروس قد وضع

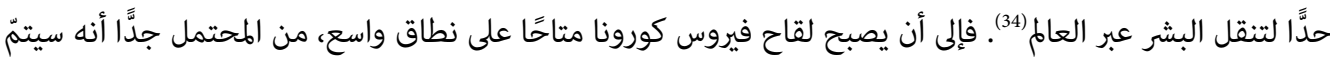
الإبقاء على القيود المفروضة على الهجرة الدولية بوجه عامّ، على الأقل في المستقبل القريب.

لقد حذرت منظمة الصحة العالية مؤخرًا من الوصول إلى مرحلة خِطِرة من الوباء مع انتشار الفيروس عبر المناطق (35).

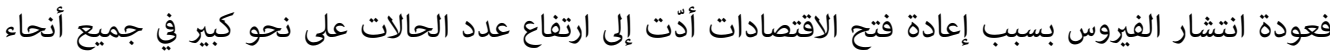

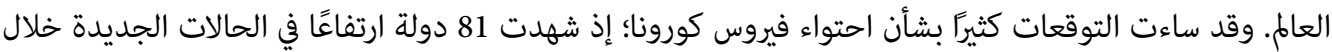

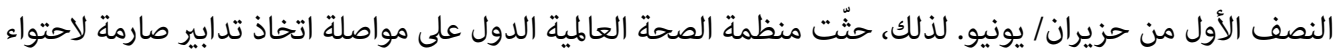

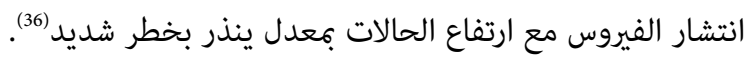

غير أن شعور الناس بالاستياء والإرهاق من جرّاء بقائهم في المنزل يتنامى يومًا بعد يوم. فهم يرغبون في العودة إلى

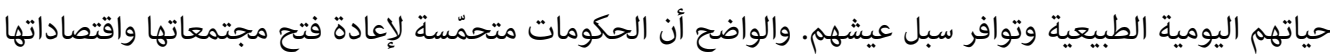

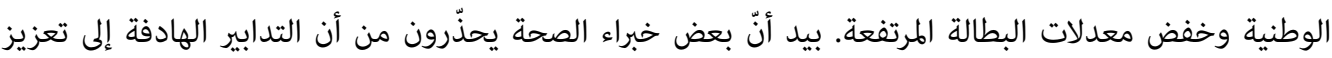

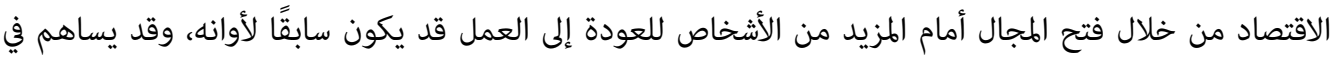
زيادة كبيرة في حالات الإصابة بفيروس كورونا.

ويبدو أيضًا أنّ أعداد اللاجئين ومُلتمسي اللجوء والكهاجرين غير الشرعيين ستشهد ارتفاعًا في المستقبل القريب بسبب الأوضاع المعيشية الصعبة ومظاهر العنف التي تفاقمت في العديد من البلدان المرسلة للمهاجرين بسبب الجائحة.

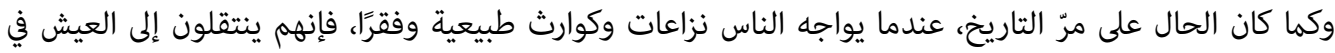

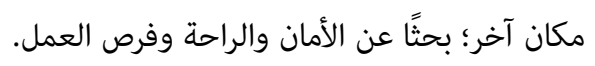

ويُذكر، على نطاق، واسع أن لقاحًا لفيروس كورونا المستجدّ قد يصبح متاحًا في أوائل عام 2021. وإنْ صِّ ذلك، فمن

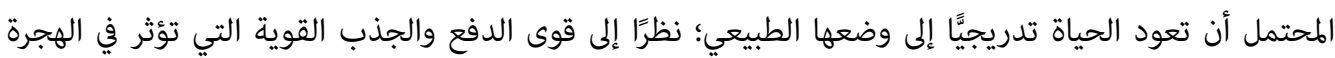
الدولية (الجدول 2).

\footnotetext{
34 Andrea Salcedo, Sanam Yar \& Gina Cherelus, "Coronavirus Travel Restrictions, across the Globe," The New York Times, 16/7/2020, accessed on 17/2/2021, at: http://nyti.ms/3dmjVXm

35 Julie Bosman, "W.H.O. Warns of Dangerous Phase as Pandemic Outbreaks Widen," The New York Times, 19/6/2020, accessed on 17/2/2021, at: http://nyti.ms/3qxFQ1A

36 Scott Neuman, "WHO Chief on COVID-19 Pandemic: "The Worst is yet to Come,"' National Public Radio, 29/6/2020, accessed on 17/2/2021, at: http://n.pr/3qw5a7X
} 


\section{الجدول (2)}

\section{قوى الدفع والجذب الرئيسة التي تحرّك الهجرة الدولية (2)}

\begin{tabular}{|c|}
\hline في بلدان المقصد: \\
\hline 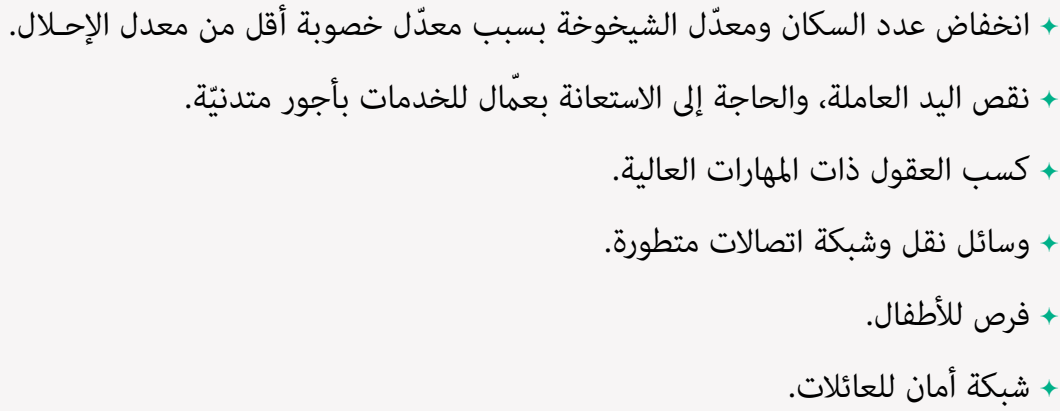 \\
\hline في بلدان المنشأ: \\
\hline 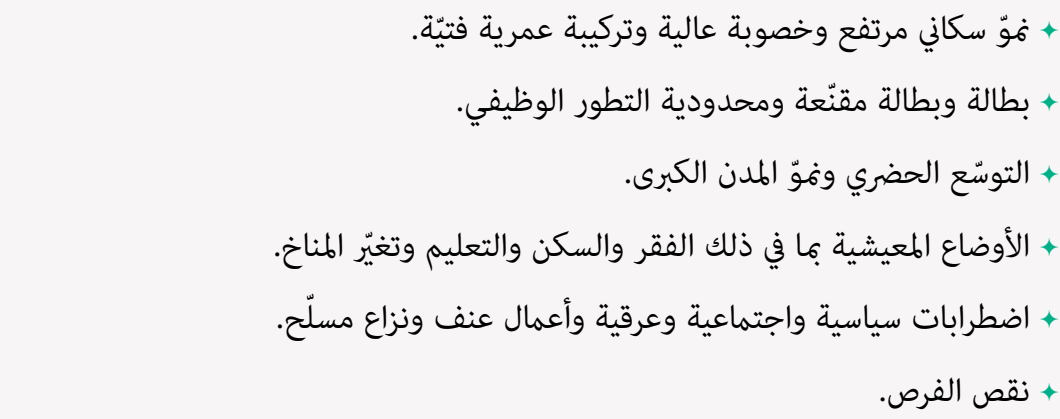 \\
\hline
\end{tabular}

من المتوقع أن يزداد عدد سكان العالم، الذي يبلغ حاليًا 7.8 مليارات نسمة، نحو ملياري نسمة إضافية بحلول

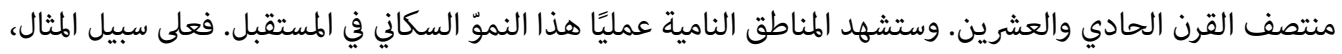
يُتوقع أن تضيف أفريقيا أكثر من مليار نسمة إلى سكانها بحلول منتصف هذا القرن. أما أوروبا، فمن المتوقع أن

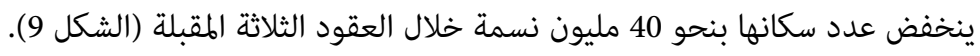

سيتضاعف عدد سكان اثنتي عشرة دولة أفريقية، كحدّ أدنى، خلال العقود الثلاثة القادمة (الشكل 10). ومن المتوقع، مثلًا، أن يتضاعف عدد سكان النيجر ثلاث مرات تقريبًا من الوقت الراهن حتى منتصف القرن، فيرتفع من 23 مليون إلى 66 مليون نسمة.

في المقابل، ستشهد العديد من البلدان المتقدمة انخفاضًا في عدد السكان، فضلًا عن وتيرة شيخوخة متسارعة. ففي

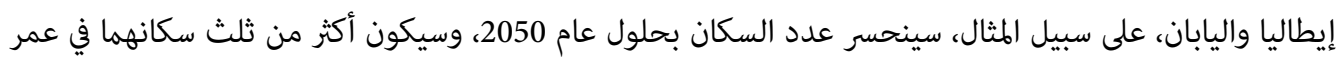

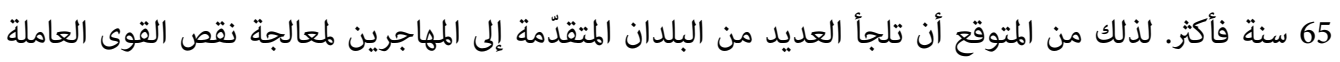

$$
\text { وتزايد أعداد كبار السن (37). }
$$

37 Martin Gelin, "Japan Radically Increased Immigration - And no one Protested," Foreign Policy, 23/6/2020, accessed on 17/2/2021, at: http://bit.ly/3jUpptE 
(الشكل 9)

ارتفاع عدد السكان في العالم والمناطق الرئيسة بين عامي 2020 و2050 (بالملايين)

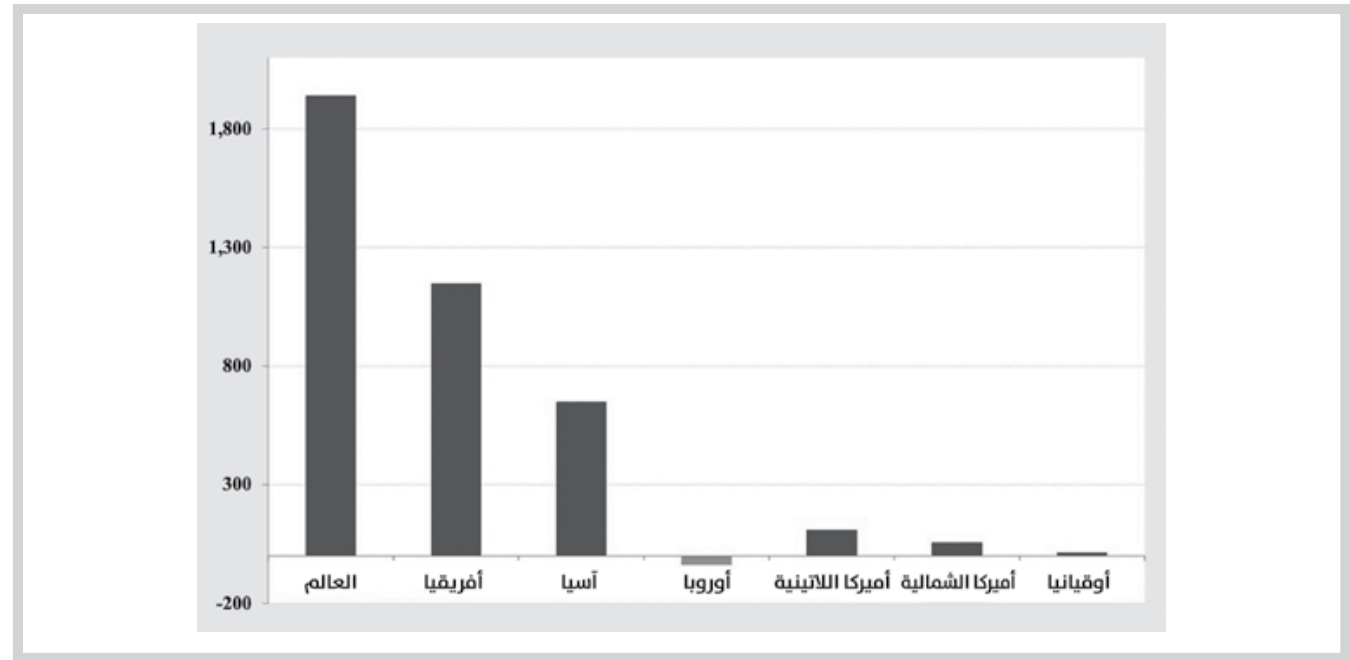

(الشكل 10)

تغيّر نسبة عدد السكان في بلدان محدّدة بين عامي 2020 و2050 (نسبة مئوية)

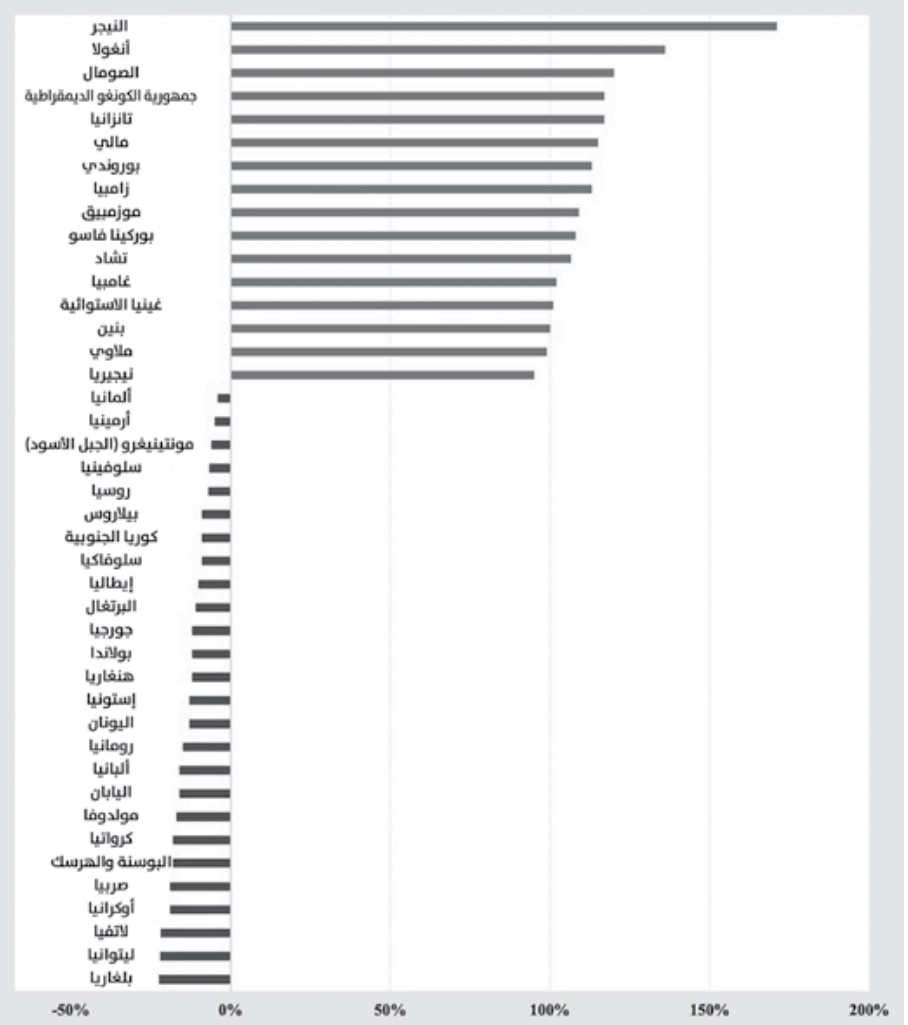


يمكن تقدير مدى التأثير المحتمل للهجرة الدولية في سكان الدول في المستقبل من خلال دراسة العدد المتوقّع للسكان

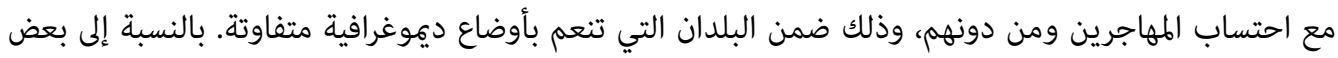

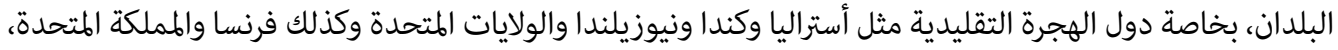
تمثل الهجرة الدولية نسبة كبيرة من النمو السكاني في المستقبل خلال العقود الثلاثة القادمة. وفي حالة كندا، سيعني

غياب الهجرة الدولية انخفاضًا بنسبة 5 في المئة تقريبًا في حجم سكانها الحالي بحلول منتصف القرن (الشكل 11).

(11) الشكل

تغيّر في نسبة عدد السكان مع احتساب الهجرة أو عدم احتسابها في الفترة 2020-2050 (نسبة مئوية)

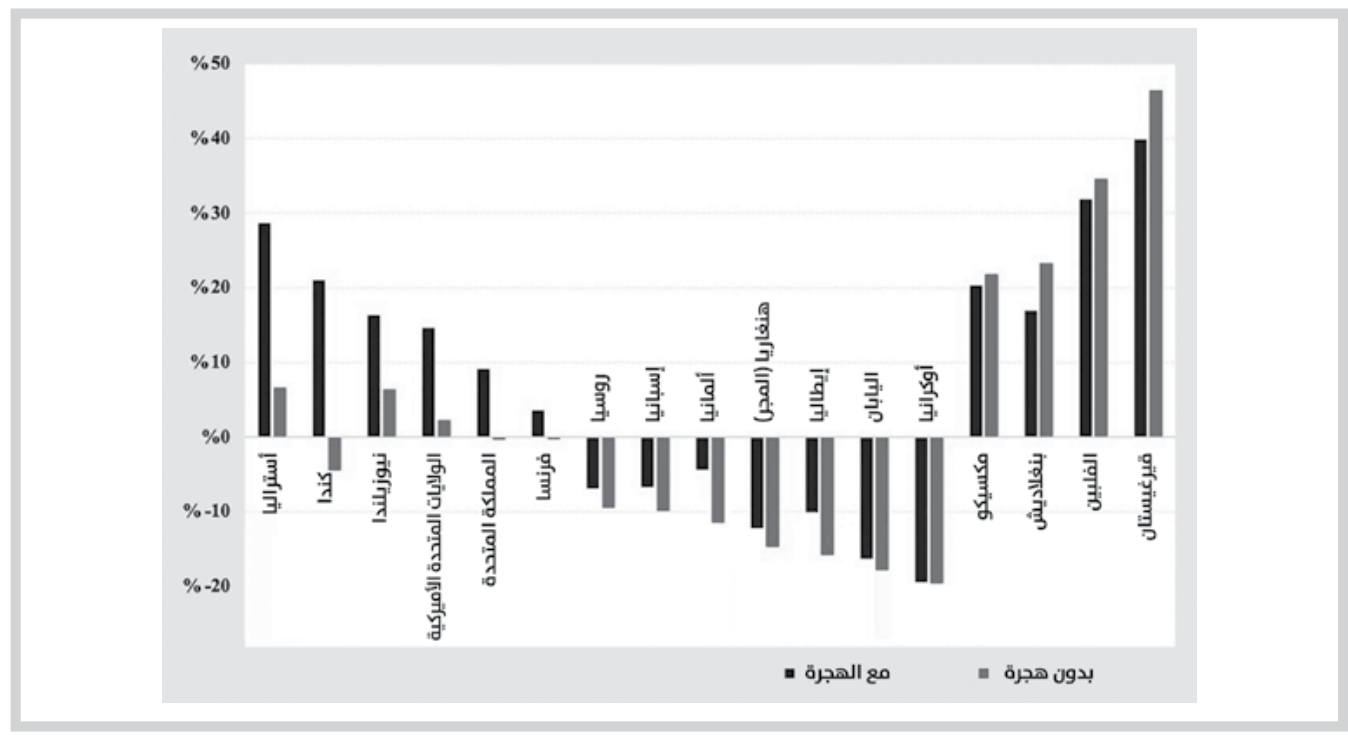

في بلدان متقدّمة أخرى، مثل ألمانيا وهنغاريا وإيطاليا واليابان وإسبانيا وروسيا وأوكرانيا، تقلّل الهجرة الدولية من الانخفاضات المتوقّعة في عدد سكانها في المستقبل بسبب معدّلاتها السلبية المتوقّعة للزيادة الطبيعية. ففي ألمانيا مثلًا، من المتوقع أن يؤدي غياب الهجرة الدولية إلى انخفاض عدد سكانها بنسبة 11 في المئة بحلول عام 2050. أما بالنسبة إلى بلدان الهجرة التقليدية، مثل بنغلاديش والمكسيك وقيرغيزستان والفلبين، فُيُقدّر أن يرتفع عدد السكان في

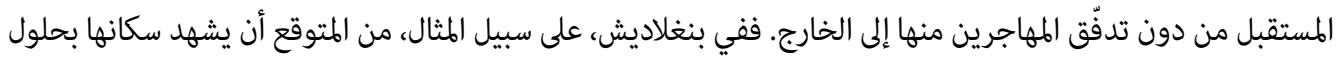
منتصف القرن الحالي زيادة بنسبة 17 في المئة مع احتساب المهاجرين مقابل زيادة بنسبة 23 في المئة من دون احتبن احتسابهم. إضافة إلى العوامل الديموغرافية، توجد عوامل دفع قوية أخرى، تؤثر في رغبة الناس في الهجرة من بلدهم. ومن

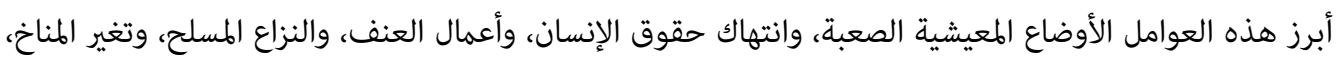

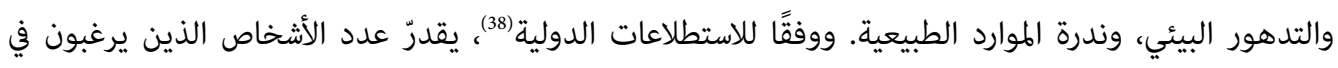

38 Neli Esipova, Anita Pugliese \& Julie Ray, "More than 750 Million Worldwide Would Migrate if They Could," Gallup News, 10/12/2018, accessed on 17/2/2021, at: https://bit.ly/37ltiTj 
الهجرة إلى بلد آخر بأكثر من مليار شخص، وهذا العدد أكبر كثيرًا من العدد الحالي الذي يبلغ 272 مليون مهاجر في

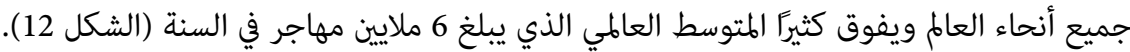

(الشكل 12)

مجموع عدد الراغبين في الهجرة ومجموع عدد المهاجرين والعدد السنوي للمهاجرين عام 2019 (بالملايين)

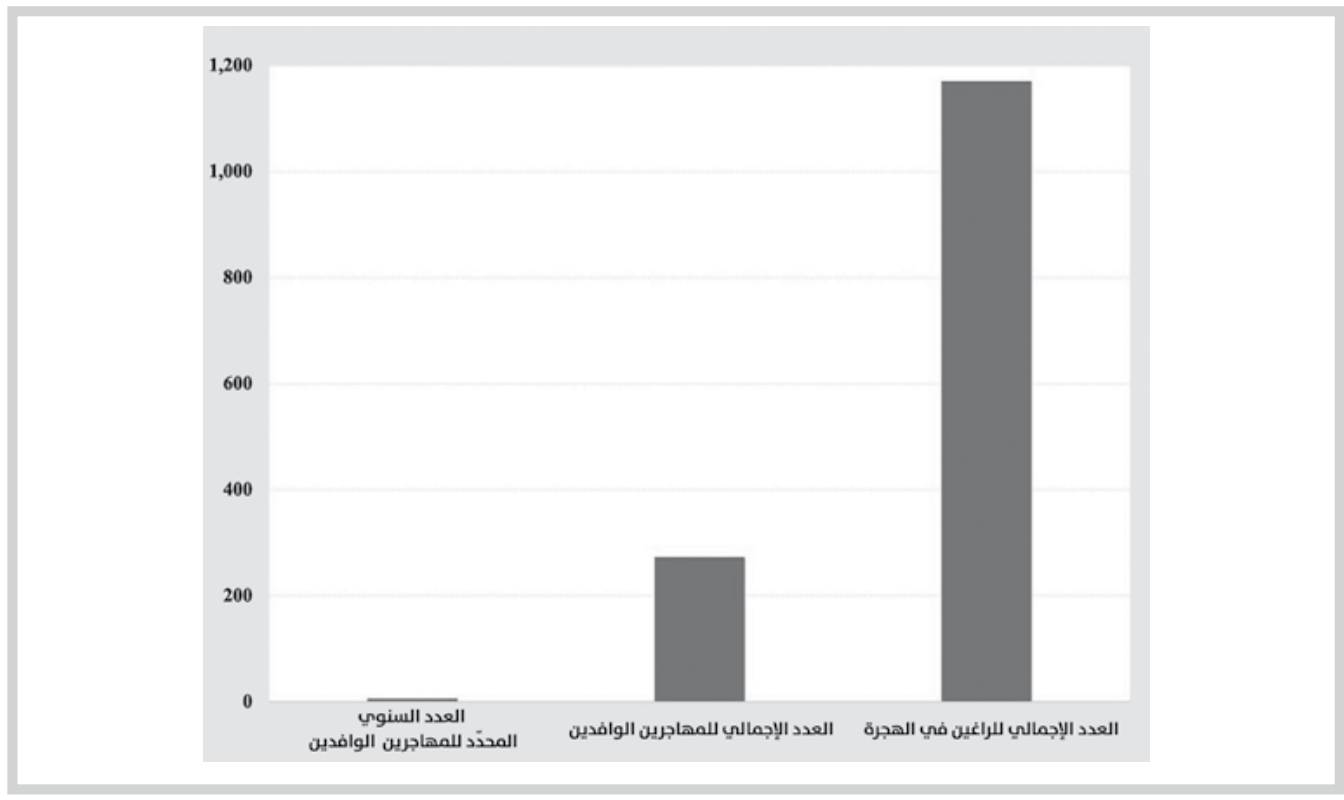

لن تكون المستويات المقبولة للهجرة الشرعية في المستقبل كافية لاستيعاب عدد ضئيل حتى ممن يرغبون في الهجرة.

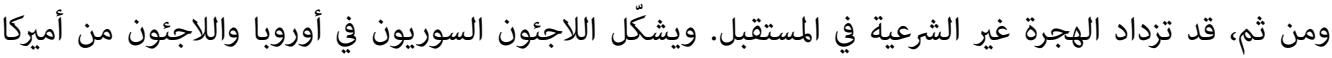

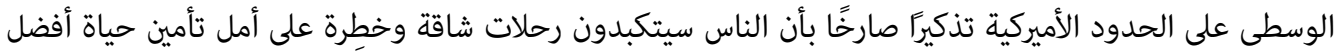
عندما لا يجدون ما يبقيهم في وطنهم.

أما الطلب على العمل وأنواعه فهو مسألة أساسية أخرى من شأنها أن تنعكس على مستويات الهجرة الدولية

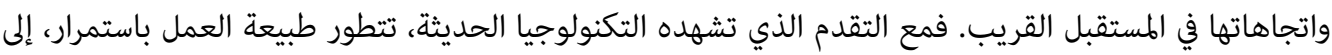

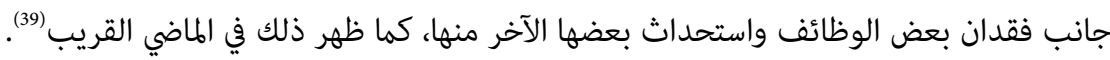
من المتوقع أن يشّكل التشغيل الآلي، بما يشمله من أقتتة وروبوتات وذكاء اصطناعي، تحولًا توازي أهميته أهمية المكننة في التصنيع والزراعة. وبحسب الاتحاد الدولي للروبوتات، فإنّ عدد الروبوتات الصناعية المنتشرة في العالم في عام 2018 يقترب من نصف مليون روبوت؛ أي نحو أربعة أضعاف عددها منذ عام 2010 (40.).

39 "Jobs Lost, Jobs Gained: What the Future of Work will mean for Jobs, Skills and Wages," McKinsey, 28/11/2017, accessed on 17/2/2021, at: http://mck.co/3u4tIXP

40 "World Robotics 2019 Preview," International Federation of Robotics, 2019, accessed on 17/2/2021, at: https://bit.ly/37jnw4n 
أشار البعض إلى أنّ هناك مخاوف بشأن خلل محتمل قد يغيّر معام المستقبل؛ إذ قد يشهد خسارة كبيرة للوظائف

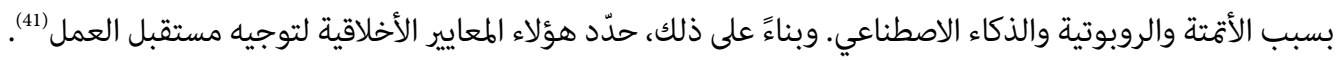

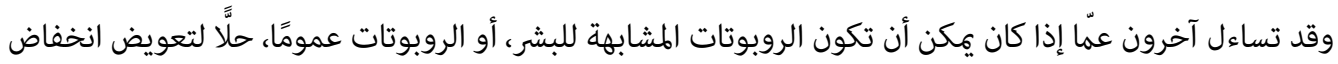

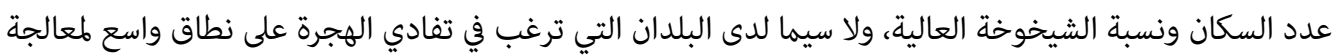
نقص القوى العاملة لديها (42).

عُرضت سيناريوهات مختلفة لتقييم أعداد الوظائف وأنواعها التي يمكن استحداثها في المستقبل، وتلك المعرّة لخطر الزوال بسبب الأتمتة. وفي حين أن الاعتماد على التكنولوجيا قد يتسبب في نزوح العمالة على المدى القصير، أظهر التاريخ أنه يفسح المجال، على المدى الطويل، لاستحداث فرص عمل جديدة وزيادة الطلب على الوظائف المتوافرة (43).

وفي وقت قد تكون فيه وظائف كافية للحفاظ على عملية التوظيف الكامل في المستقبل القريب، من المتوقع أن يشكّل التبديل في المهن تحديًا كبيرًا، حيث سيحتاج العديد من العمال إلى اكتساب مهارات جديه ويدة.

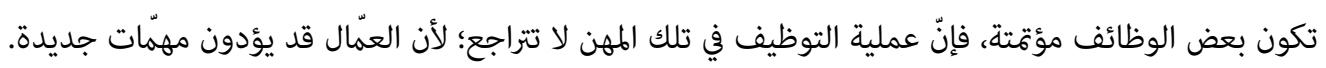

ثمّ إنّ أنشطة العمل في البيئات التي لا يمكن التنبؤ بها، مثل تلك التي توفّر الخدمات الصحية والطبية ورعاية

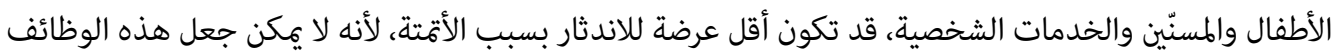

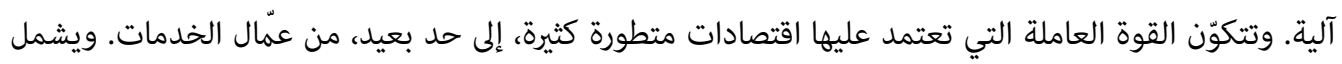

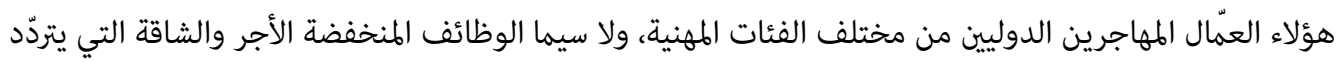
أغلبية العمال المحليين في القيام بها. وقد سلطت جائحة فيروس كورونا الضوء على المساهمات الحيوية التي يقوم بها العديد من عمّال الخدمة المهاجرين.

على وجه الإجمال، ينقسم الرأي العامّ في العالم بشأن مسألة زيادة مستويات الهجرة الحالية أو خفضها أو الحفاظ

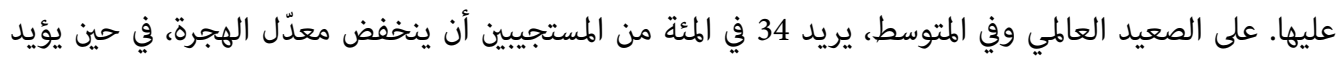

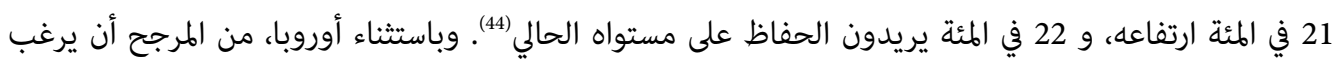
سكان كل منطقة رئيسة في أن تحافظ الهجرة في بلدانهم إما على مستواها الحالي، وإما أن تشهد ارتفاعًا في معدّلاتها بدلًا من أن تتراجع.

غير أنّ عددًا متناميًا من الدول باتت ترى في الهجرة غير الشرعية تهديدًا خِطرًا للسيادة والأمن الوطنيين، وتقويضًا

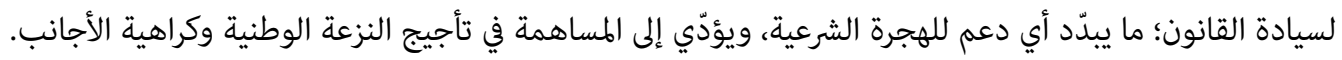
وبالنسبة إلى العديد من القوميين والأحزاب السياسية اليمينية المتطرفة ومؤيديهم، باتت التركيبة السكانية المتغيرة

41 Donald Kerwin, "International Migration and Work: Charting an Ethical Approach to the Future," Journal on Migration and Human Security, vol. 8, no. 2 (2020), pp. 111-133.

42 Joseph Chamie, "Robots: A Solution to Declining and Aging Populations?" Inter Press Service, 4/9/2017, accessed on 17/2/2021, at: http://bit.ly/3bi7UiQ

43 "Jobs Lost, Jobs Gained."

44 "How the World Views Migration," International Organization for Migration (IOM), accessed on 17/2/2021, at: https://bit.ly/3u98Z5p 
تُختصر في "القليل جدَّا منّا والكثير الكثير منهم"(45). وبحسب هؤلاء، تشبه الديموغرافيا "القَدر"، كما أنهم يعتبرون التغيرات الديموغرافية التي أحدثتها الهجرة الدولية مقوّضة لأسلوب حياتهم الأساسي. شهد النزوح الذي حدث مؤخرًا نطاقًا غير مسبوق أدّى إلى إنهاك نظام اللاجئين العالمي على نحو لا يخفى على أحد؛ إذ كانت الوكالات الإنسانية والمجتمعات المضيفة تكافح لتوفير الاحتياجات المتزايدة بصورة دائمة. وقد أعلنت المفوضية السامية للأمم المتحدة لشؤون اللاجئين ما يلي: "إننا نشهد تغييرًا في فوذج ينزلق سريعًا إلى عصر أصبح فيه حجم النزوح القسري العالمي والاستجابة المطلوبة له لا يضاهيهما أي شيء سابق"(46).

\section{ملاحظات عامة ومبادئ لتوجيه صنع السياسات}

يواجه العالم اليوم أزمة مفاجئة وفتّاكة بسبب جائحة فيروس كورونا المستجدّ. فبحلول منتصف عام 2020، أُعلن عَّا لا يقل عن 12 مليون حالة إصابة بفيروس كورونا وأكثر من نصف مليون حالة وفاة. لقد تحوّلت جائحة كوفيد-19 من كونها أزمة صحيّة إلى أسوأ أزمة اقتصادية واجتماعية في العصر الحديث (47).

لا يزال صدى آثار فيروس كورونا الواسع النطاق يتردد في جميع أنحاء العالم، ولا تزال مسألة تخطي هذه الأزمة مبهمة. فمنظمة الصحة العالهية تحذر من أنه مع قيام الدول بتخفيف قيود الإغلاق، لا يزال خطر حصول الأسوأ

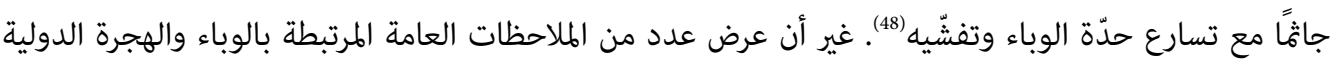

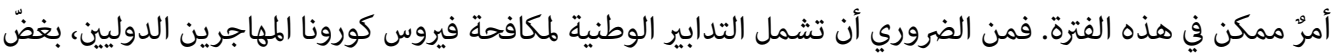
النظر عن وضعهم القانوني، وينبغي أيضًا أن تكون استكمالًا للاستجابات الإقليمية والدولية.

على الرغم من إرادة الحكومات منْعَ دخول فيروس كورونا وانتشاره الفتّاك بين سكانهم، ومساعيها في هذا الشأن، فإنّ الجميع بات اليوم، وبخاصة قادة الحكومات، مدركين تامًا أن فيروس كوفيد-19 "لا يحترم" الحدود الدولية ولا السيادة الوطنية. فمن دون تأشيرة أو إذنٍ رسمي للدخول، انتشر الفيروس في غضون بضعة أشهر بسرعة كبيرة عبر القارات وداخل البلدان في جميع أنحاء العالم.

وعلى عكس الحكومات، لا يهتم الفيروس بالجنسية أو المواطنة أو وضع الهجرة. إنه ببساطة لا يأبه بمثل هذه الأمور. فالأمر ليس شخصيًّ بالنسبة إلى هذا الفيروس المميت، بل إنه يرتبط بعلاقة عمل بحتة تتمثل بإصابة البشر، ونشر العدوى، وربما وضع حذّ لحياة البشر.

45 Joseph Chamie, "Global Population: Too Few versus Too Many," YaleGlobal, 31/3/2020, accessed on 17/2/2021, at: http://bit.ly/3s2KPHW

46 UNHCR, UNHCR Warns of Dangerous New Era in Worldwide Displacement as Report Shows Almost 60 Million People Forced to Flee Their Home, 18/6/2015, accessed on 17/2/2021, at: http://bit.ly/3bcSxs1

47 Gareth Willmer \& Fiona Broom, "Covid-19 Has Stalled UN's Goals to Reduce Global Hunger, Poverty, and Climate Change," Scroll.in, 1/6/2020, accessed on 17/2/2021, at: http://bit.ly/2OO614L

48 Neuman, p. 13. 
لا تزال العديد من الدول وقادة العالم منقسمة بشأن كيفية مكافحة فيروس كورونا(49). فمنظمة الصحة العالمية ترى أن الافتقار إلى الوحدة والتضامن العالمي يساهم في انتشار الفيروس. وفي هذا السياق، إضافة إلى المبادئ التوجيهية

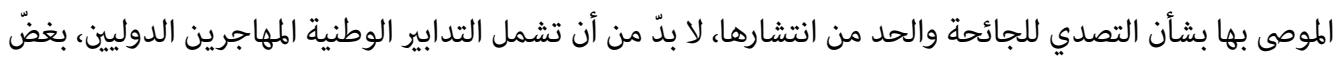

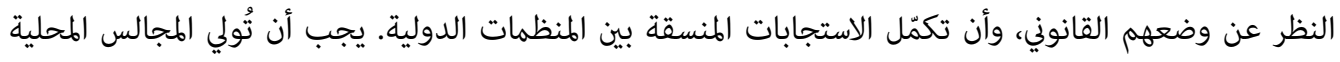
والدول والمجتمع الدولي الأولوية لعودة المهاجرين الآمنة ولإعادة دمجهم.

لقد تسبّبت الجائحة في وقف حركة الإنسان على نطاق كبير، وهو أمرٌ غير مسبوق في العصر الحديث (50) إضافة إلى القيود العالمية على السفر الدولي، وتأثر مليارات الأشخاص بتداعيات الجائحة الاقتصادية الواسعة النطاق تأثرًا

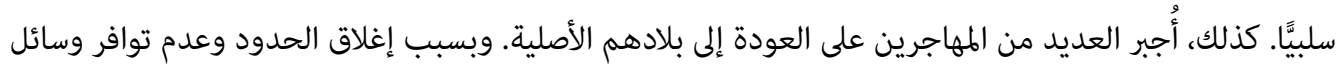
النقل، وجد بعض المهاجرين أنفسهم معزولين، وقد تقطعت بهم السبل، في أوضاع معيشية صعبة، وفي مراكز

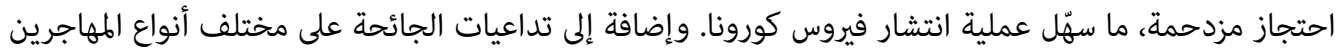

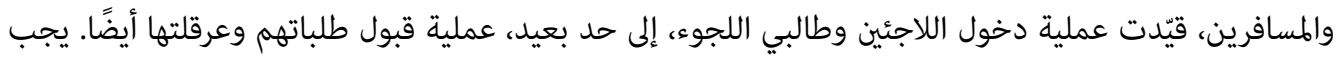

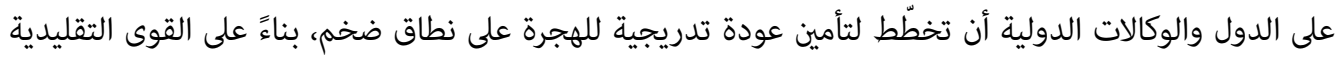
للدفع والجذب، ما إن يتوافر لقاح ضدّ فيروس كوفيد-19 على نطاق واسع.

تعتمد العودة إلى مستويات الهجرة الدولية واتجاهاتها، التي كانت قائمة في الماضي القريب، على توافر لقاح فعّال.

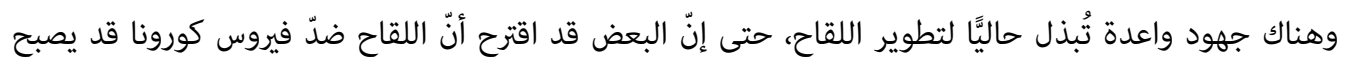

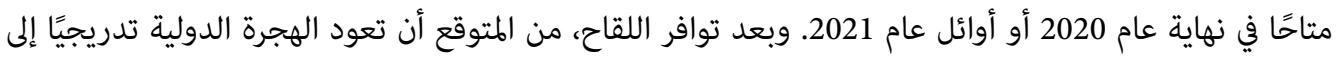
مستوياتها السابقة قبل فترة ظهور الوباء. فخلال نصف القرن الهاضي، أصبحت الهجرة الدولية مكونًا أساسيًا وضروريًا للاقتصاد المعوز؛؛ إذ تعتمد العديد من البلدان على الهجرة لتعزيز النمو الاقتصادي المستقبلي فئ.

مل تتبذد قوى الدفع والجذب الشديدة التي انعكست على اتجاهات الهجرة الدولية ومستوياتها في الماضي، بل إنّ هذه القوى ستعاود الظهور وتفرض نفسها في المستقبل. وعلى نحو خاص، سيؤدي النمو السكاني السريع في البلدان

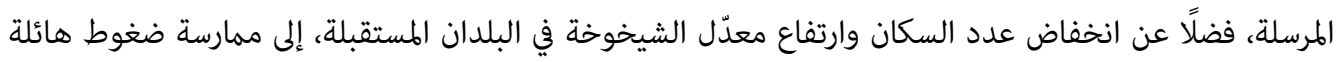

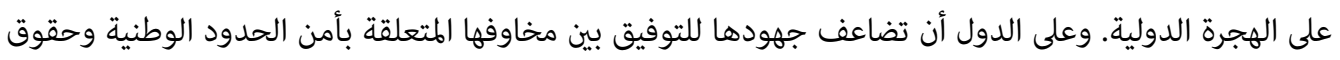
الإنسان الأساسية للمهاجرين واللاجئين وطالبي اللجوء. وقد تشهد نسبة الهجرة غير الشرعية ارتفاعًا حتى في حال

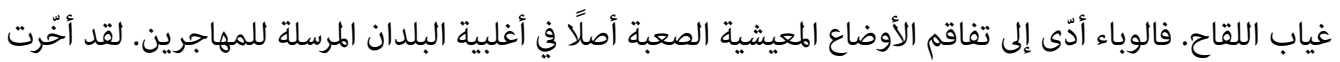

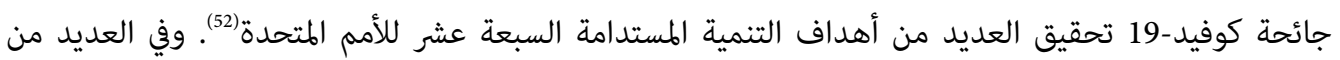

49 Will Feuer \& Jasmine Kim, "WHO Warns Coronavirus Pandemic is Speeding up as Countries Ease Lock-down Rules: 'The Worst is yet to Come," CNBC, 29/6/2020, accessed on 17/2/2021, at: http://cnb.cx/3u0m14W

50 Kirk Semple, "As World Comes to Halt amid Pandemic, So Do Migrants," The New York Times, 4/5/2020, accessed on 17/2/2021, at: https://nyti.ms/3s2cxEB

51 Jeanna Smialek \& Zolan Kanno-Youngs, "Why aTop Trump Aide Said, 'We Are Desperate' for more Immigrants," The New York Times, 27/2/2020, accessed on 17/2/2021, at: http://nyti.ms/3qxN6dQ

$$
52
$$

United Nations: Economic and Social Council, Progress towards the Sustainable Development Goals, 25 July 2019-22 July 2020, accessed on 17/2/2021, at: https://bit.ly/2ODriza 
البلدان النامية، أدت تدابير الحدّ من تأثير الوباء إلى استنزاف النظام الصحي عالميًا وإغلاق الشركات والمصانع، وأثرت

$$
\text { أيضًا بشدة في سُبل عيش الكثير من القوى العاملة (53). }
$$

بصورة خاصة، يؤدي عدم الاستقرار الاقتصادي والمجاعة وانتهاكات حقوق الإنسان والاضطرابات الاجتماعية

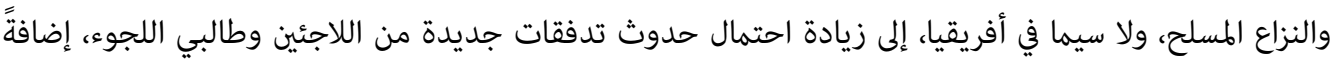

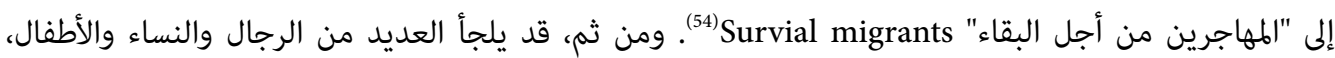
الذين لديهم فرصة ضئيلة في الهجرة من خلال الوسائل القانونية، إلى الهجرة غير الشرعية لتحسين أوضاعهم المعيشية العصيبة والمتفاقمة.

تشكّل تبعات الهجرة غير الشرعية، فضلًا عن المخاطر الكبيرة التي يتعرّض لها المهاجرون، تحدّيًا خطِرًا لقدرات السلطات الحكومية والمنظمات الحكومية الدولية وأوضاعها المالية، علاوة على مواقف عامة السكان تجاه الهرهي المهاجرين. وقد ازداد الوضع تعقيدًا بسبب جائحة فيروس كورونا التي منحت أصحاب النزعة القومية وغيرهم "مبررًا" لإبقاء

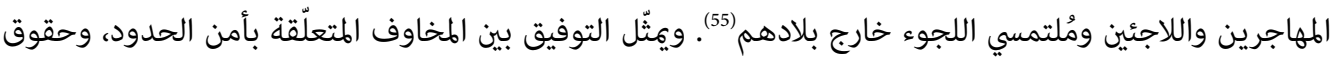

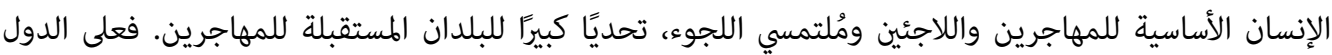
والمجتمع الدولي تسريع جهودهم لمعالجة مسألة المهاجرين الذين ترتبط هجرتهم بالتغيرات المناخية. يُتوقّع في العقود القادمة أن تصبح الهجرة المرتبطة بالمناخ تحديًا أكثر خطورة مما هي عليه اليوم؛ إذ ستضطر أعداد

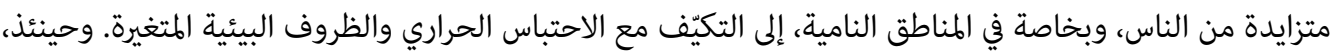

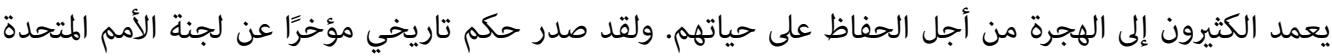

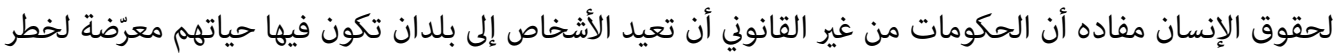
بسبب أزمة المناخ (56). وبحسب هذا الحكم، قد ينزح عشرات الملايين من الأشخاص ويتحوّلون إلى لاجئين في المستقبل

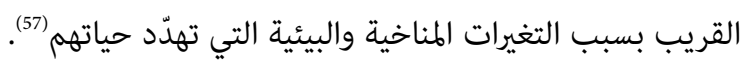

بحلول منتصف القرن، وبحسب تقديرات البعض، قد ينجم عن تغير المناخ نحو مليار لاجئ بيئي (58). وعلى عكس

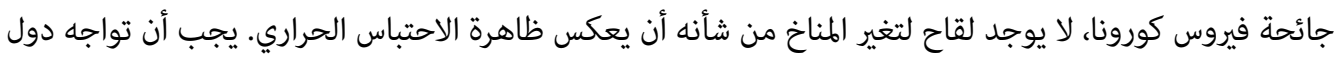
المنشأ والعبور والمقصد تحديات الهجرة الدولية على نحو مباشر، وألّا تقلّل من شأنها.

أخيرًا، ستبقى الهجرة الدولية، وفي عالم ما بعد كورونا، مُعزّزة للفرص التنموية المتاحة للجماعات والدول والمنظمات

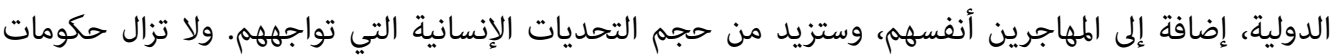

53 Ibid.

54 Alexander Betts, Survival Migration: Failed Governance and the Crisis of Displacement (Ithaca, NY: Cornell University Press, 2013).

55 Somin.

56 Kate Lyons, "Climate Refugees Can't Be Returned Home, Says Landmark UN Human Rights Ruling," The Guardian, 20/1/2020, accessed on 17/2/2021, at: https://bit.ly/2OGZcmB

57 Matthew Taylor, "Climate Change 'Will Create World's Biggest Refugee Crisis," The Guardian, 2/11/2017, accessed on 17/2/2021, at: http://bit.ly/3jY3HVv

58 Frank Laczko \& Christine Aghazarm, "Migration, Environment and Climate Change: Assessing the Evi-dence," International Organization for Migration (IOM), 2009, accessed on 17/2/2021, at: https://bit.ly/2LZtH6v 
بلدان المنشأ والعبور والمقصد والوكالات الدولية والمنظمات غير الحكومية تواصل البحث عن أفضل السبل لمواجهة التحديات التي تفرضها الأعداد المتزايدة من المهاجرين، واللاجئين، وطالبي اللجوء، والنازحين.

إن إنكار التحديات التي تفرضها الهجرة الدولية أو التقليل من شأنها لن يجعلها تختفي، ولن يقلّل من عواقبها

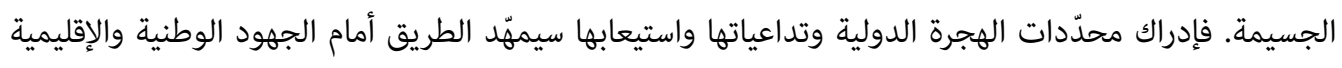
والدولية لصياغة سياسات ذات فاعلية وأمام تطوير البرامج المناسبة.

\section{الإعلان الخاص حول تضارب المصالح}

أعلن المؤلف عدم وجود تضارب محتمل في المصالح في ما يتعلّق بالبحث والتأليف و/ أو نشر هذه الورقة.

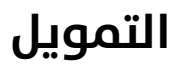

مل يحصل المؤلف على أي دعم مالي للقيام بأبحاث وتأليف و/ أو نشر هذه الورقة. 
Appleby, Kevin J. "Implementation of the Global Compact on Safe, Orderly, and Regular Migration: A Whole-of-Society Approach." Journal on Migration and Human Security. vol. 8, no. 2 (2020).

Betts, Alexander. Survival Migration: Failed Governance and the Crisis of Displacement. Ithaca, NY: Cornell University Press, 2013.

Bier, David J. "How Travel Bans Failed to Stop the Spread of COVID-19." Cato Institute. at: https://bit.ly/37ollg3

Boghean, Carmen. "The Phenomenon of Migration: Opportunities and Challenges." USV Annals of Economics and Public Administration. vol. 16, no. 3 (2016). at: https://bit.ly/3rVYRe4

Castles, Stephen, Hein de Haas \& Mark J. Miller. Age of Migration: International Population Movements in the Modern World. $5^{\text {th }}$ ed. London: Palgrave Press, 2014.

Chamie, Joseph. "Human Trafficking in the $21^{\text {st }}$ Century." Foreign Policy Association. Great Decisions, 2015 Briefing Book. at: http://bit.ly/3s0ZvHh

Chamie, Joseph. "International Migration amid a World in Crisis." Journal on Migration and Human Security. vol. 8, no. 3 (2020).

Chamie, Joseph. "Robots: A Solution to Declining and Aging Populations?" Inter Press Service. at: http://bit.ly/3bi7UiQ

Chishti, Muzaffar \& Sarah Pierce. "The U.S. Stands Alone in Explicitly Basing CoronavirusLinked Immigration Restrictions on Economic Grounds." Migration Information Source, Migration Policy Institute (2020).

Connor, Phillip. "More than Nine-in-Ten People Worldwide Live in Countries with Travel Restrictions amid Covid-19." Pew Research Center. at: http://pewrsr.ch/2ZmH5V5

"How the World Views Migration." International Organization for Migration (IOM). at: https://bit.ly/3u98Z5p

"International Migration Outlook 2019." OECD iLibrary. at: http://bit.ly/3jXAVEy

"Kerwin, Donald. "International Migration and Work: Charting an Ethical Approach to the Future." Journal on Migration and Human Security. vol. 8, no. 2 (2020).

Kluge, Hans Henri P. et al. "Refugee and Migrant Health in the COVID-19 Response." The Lancet. vol. 395, no. 10232 (2020). at: https://bit.ly/3pstoii 
Laczko, Frank \& Christine Aghazarm. "Migration, Environment and Climate Change: Assessing the Evi-dence." International Organization for Migration (IOM). 2009. at: https://bit.ly/2LZtH6v "Managing International Migration under COVID-19." OECD. at: https://bit.ly/3qG0Oeo Somin, Ilya. "The Danger of America's Coronavirus Immigration Bans." The Atlantic. at: http://bit.ly/3qvnRbM

UNHCR. UNHCR Warns of Dangerous New Era in Worldwide Displacement as Report Shows Almost 60 Million People Forced to Flee Their Home. at: http://bit.ly/3bcSxs1

United Nation, Department of Economic and Social Affairs Population Dynamics. "Population Division: World Population Prospects 2019, Definition of Regions." at: https://bit.ly/2NbNqQM

United Nations High Commissioner for Refugees (UNHCR). "Global Trends: Forced Displacement in 2019." at: https://bit.ly/3jY9zhB

United Nations. Report of The United Nations High Commissioner for Refugees. Global Compact on Refugees (New York: 2018). at: https://bit.ly/2LYQ4cd

United Nations Economic and Social Council. Progress towards the Sustainable Development Goals. 25 July 2019-22 July 2020. at: https://bit.ly/2ODriza

United Nations, General Assembly. "Draft Outcome Document of the Conference." 2018. at: http://bit.ly/2NC6c3z

United Nations, Office for Drugs and Crime (UNODC). COVID-19 Measures Likely to Lead to an Increase in Migrant Smuggling and Human Trafficking in Longer Term, UNODC Report Finds. at: https://bit.ly/3qw37Rj

World Bank. "World Bank Group: 100 Countries Get Support in Response to COVID-19 (Coronavirus)." at: http://bit.ly/2LY6xxb

. "World Bank Predicts Sharpest Decline of Remittances in Recent History." at: http://bit.ly/3ua2bVc

"Migration, Remittances, Diaspora and Development." KNOMAD. at: http://bit.ly/3rYLRoc . Remittances Data. 2020. KNOMAD. at: https://bit.ly/3rYLRoc

"World Robotics 2019 Preview." International Federation of Robotics, 2019. at: https://bit.ly/37jnw4n 